\title{
Super-sized tensions and slim responses? The discursive construction of strategic tensions around social issues
}

DOI:

10.5465/AMBPP.2018.10792

\section{Document Version}

Accepted author manuscript

Link to publication record in Manchester Research Explorer

\section{Citation for published version (APA):}

Pinkse, J., Hahn, T., \& Figge, F. (2019). Super-sized tensions and slim responses? The discursive construction of strategic tensions around social issues. Academy of Management Discoveries, 5(3), 314-340.

https://doi.org/10.5465/AMBPP.2018.10792

\section{Published in:}

Academy of Management Discoveries

\section{Citing this paper}

Please note that where the full-text provided on Manchester Research Explorer is the Author Accepted Manuscript or Proof version this may differ from the final Published version. If citing, it is advised that you check and use the publisher's definitive version.

\section{General rights}

Copyright and moral rights for the publications made accessible in the Research Explorer are retained by the authors and/or other copyright owners and it is a condition of accessing publications that users recognise and abide by the legal requirements associated with these rights.

\section{Takedown policy}

If you believe that this document breaches copyright please refer to the University of Manchester's Takedown Procedures [http://man.ac.uk/04Y6Bo] or contact uml.scholarlycommunications@manchester.ac.uk providing relevant details, so we can investigate your claim.

\section{OPEN ACCESS}




\section{SUPER-SIZED TENSIONS AND SLIM RESPONSES? THE DISCURSIVE \\ CONSTRUCTION OF STRATEGIC TENSIONS AROUND SOCIAL ISSUES}

Dr Jonatan Pinkse

Alliance Manchester Business School

The University of Manchester

Booth Street West

Manchester M15 6PB

United Kingdom

Email: jonatan.pinkse@manchester.ac.uk

Tel.: +44161275 7375

Dr Tobias Hahn

Professor of Business Sustainability

ESADE Business School Barcelona

Ramon Llull University

Avenida de Torreblanca, 59

08172 Sant Cugat

Spain

Email: tobias.hahn@esade.edu

Tel.: +34 932806162 (ext. 2754)

Honorary Professor

University of Sydney Business School

The University of Sydney

NSW 2006

Australia

Dr Frank Figge

KEDGE Business School Marseille

Domaine de Luminy - BP 921 
13288 Marseille Cedex 9

France

Email: figge@sustainablevalue.com

Tel.: +33761525218

Visiting Professor

Macquarie Business School

Macquarie University

Sydney, NSW

Australia

\section{Acknowledgements}

We would like to thank the action editor Thomas Dyllick and two anonymous reviewers for their valuable comments and suggestions on our paper. 


\begin{abstract}
Companies producing and marketing processed high-fat-high-sugar food and drinks face a strategic tension between their core business and the social issue of obesity. For these companies, the social issue of obesity constitutes a strategic social-business tension. We conduct a qualitative study of the print media coverage on the public debate around obesity to analyse how companies discursively respond to strategic tensions around this widely salient issue. We identify the accepting-defensive approach to strategic social-business tensions that companies employ to protect the autonomy over their core business vis-à-vis pressures and demands from the public debate around obesity. We unearth the two discursive mechanisms - choice of discursive tactics and construction of tensions - that underlie this accepting-defensive approach. In contrast to what the literature on organisational tensions suggests, corporate responses to strategic tensions go beyond the dichotomy of acceptingconstructive and rejecting-defensive responses. We offer a better understanding of the discursive mechanisms that companies use to maintain autonomy when facing strategic tensions around widely salient social issues.
\end{abstract}

Keywords: social-business tensions; obesity; food and drink industry; public discourse; widely salient issues; strategic autonomy; sustainable development goals 


\section{INTRODUCTION}

In the food and beverage industry, the social issue of obesity constitutes a strategic tension that challenges the core business of companies producing and marketing highly processed food Iivonen (2018). In 2013, one in three adults worldwide was overweight or obese and adult obesity was exceeding $50 \%$ in several countries around the globe; obesity has become a pandemic and a widely salient social issue (Hruby \& Hu, 2015; Swinburn et al., 2011). With a growing consensus that the increasing consumption of highly processed food with high sugar and/or fat content is a key factor in the prevalence of obesity (Stuckler, McKee, Ebrahim, \& Basu, 2012), food and beverage companies face public pressure to lower their products' fat and sugar content to help consumers have healthier diets (Mudd, 2013; Stuckler \& Nestle, 2012; The PLoS Medicine Editors, 2012). For these companies, obesity constitutes a strategic tension between business and social goals as the more these companies move away from offering high-fat-high-sugar (HFHS) food in response to the public pressure to tackle obesity, the more their core business that relies on HFHS foods is jeopardized. This tension is spurred by increased societal pressure upon companies to make a positive contribution to social progress by addressing social issues such as those related to the UN Sustainable Development Goals (SDG) that are considered 'grand challenges' (George, Howard-Grenville, Joshi, \& Tihanyi, 2016). In particular, 'widely salient' social issues such as obesity (Bonardi and Keim (2005) — i.e. issues that are highly relevant for public policy and receive extensive media attention—often challenge companies' core business activities and therefore lead to strategic tensions (Sharma \& Good, 2013). ${ }^{1}$

To date, only a few studies have made headway into understanding how food companies

\footnotetext{
${ }^{1}$ While the SDGs represent grand challenges not all SDGs are widely salient social issues in that not all of them are subject to regulatory activity and receive widespread attention in the public discourse. With grand challenges, the focus is less on public attention, but on finding ways to "help solve an important societal problem with a high likelihood of global impact through widespread implementation" (George et al., 2016: 1881). Due to our focus on food and drink companies' discursive responses to the public debate around obesity, we frame our analysis around Bonardi and Keim's (2005) notion of widely salient issues rather than around grand challenges.
} 
respond to the strategic tension between their processed-food-based business and obesity (Iivonen, 2018; Karnani, McFerran, \& Mukhopadhyay, 2014; Wansink \& Huckabee, 2005). Similar to other contested industries (e.g., tobacco or gambling), food companies only reluctantly act on stakeholder pressure because drastic measures would challenge their core business practices (Brownell \& Warner, 2009). The literature on organisational tensions assumes that actively engaging tensions is conducive to constructive responses to tensions around social concerns, while a rejection of such tensions is linked to defensive responses (Hahn, Pinkse, Preuss, \& Figge, 2015; Smith \& Lewis, 2011). However, because it is a widely salient issue, there is a public debate about obesity. Therefore, food companies cannot simply reject the social issue but need to deal with the resulting strategic tensions. In this paper, we therefore ask: How do companies respond to strategic tensions between their core business and widely salient social issues in their engagement in the public discourse?

Through a qualitative study, we analyse how food and beverage companies address the strategic social-business tensions around obesity in the public debate on obesity in the UK. Using data from newspapers and trade journals, we examine how food companies and retailers conceive strategic tensions between fighting obesity and marketing processed HFHS food in the public debate. We find that in response to strategic tensions food and beverage companies apply two distinct discursive mechanisms to protect their autonomy over the strategic direction they wish to take in relation to pressures from the public debate: choice of discursive tactics and construction of tensions. Food companies tried to neutralise or weaken the strategic tension by combining three different discursive tactics — questioning, tying up, and capturing - with efforts to either deconstruct or reconstruct the strategic tension around obesity. These combinations result in six different discursive response patterns.

As our main contribution, we identify the accepting-defensive approach to strategic social-business tensions and its two underlying mechanisms - choice of discursive tactics and 
construction of tensions. Together this explains how food companies seek to protect their core business in the face of strategic tensions around widely salient social issues and keep autonomy over the future direction of their business. Our evidence suggests that the accepting-defensive approach can represent a transitory stage and improves our understanding of responses to strategic tensions beyond a black-and-white picture of either rejectingdefensive or accepting-constructive responses to tensions. By offering insights into the underlying mechanisms of organisational responses to strategic tensions (Smith, 2014), we show that companies adopt a variety of accepting-defensive responses by purposefully and actively engaging strategic tensions, albeit with the aim to maintain autonomy over the future direction of their core business vis-à-vis public pressures. Our findings suggest that - contrary to the main argument in the literature on organisational tensions - accepting and engaging strategic tensions does not necessarily result in constructive responses and desirable social outcomes (Hahn, Preuss, Pinkse, \& Figge, 2014). Rather, companies' engagement in the public discourse is a double-edged sword: While it commits them to tackling obesity, they also seek to influence the discourse in their own preferred direction. Furthermore, our findings suggest that organisational responses to the public discourse around social issues are not only determined by discursive tactics (Oliver, 1991) but also by purposeful efforts to deor reconstruct strategic tensions.

\section{STRATEGIC TENSIONS AROUND THE WIDELY SALIENT SOCIAL ISSUE OF \\ OBESITY}

In this paper, we address the public health issue of obesity in the food and beverage industry to analyse how companies deal with strategic tensions stemming from the public discourse around widely salient social issues. In the following, we provide an overview on the obesity pandemic and corporate responses to it, before arguing why obesity constitutes a strategic tension for companies in this sector. 


\section{Tensions around Widely Salient Social Issues: The Case of Obesity}

The obesity pandemic as a widely salient social issue. Over the last three decades, many societies in Western countries, but also in emerging economies, have witnessed a dramatic increase in overweight and obesity (Hruby \& Hu, 2015; Swinburn et al., 2011). Recent data shows that, worldwide, more than 2.1 billion people are overweight or obese, increasing the rate of diseases such as various types of cancer, Type 2 diabetes, depression, and cardiovascular diseases, resulting in immense costs for healthcare systems. Accounting for around 3.4 million deaths annually, overweight and obesity are the fifth leading cause of death in the world (Smith \& Smith, 2016). A particularly alarming trend is the rise of obesity among children and adolescents (Ebbeling, Pawlak, \& Ludwig, 2002; Papoutsi, Drichoutis, \& Nayga, 2013). Obesity has been linked to a complex set of genetic, environmental, socioeconomic and behavioural sources, with trends towards industrialisation, mechanised transport, urbanisation, and increasingly sedentary lifestyles, and a nutritional transition towards processed foods and high-calorie diets playing important roles (Hruby \& $\mathrm{Hu}, 2015$ ).

With regard to the role of nutrition, there is growing evidence that the increase in obesity 'seems to be driven mainly by changes in the global food system, which is producing more processed, affordable, and effectively marketed food than ever before' (Swinburn et al., 2011: 804). The promotion of large portion sizes, the availability of fast food, and omnipresent food advertisement have led to an increasing consumption of processed foods that mainly derive their energy from fats and sugars (James, Leach, Kalamara, \& Shayeghi, 2001). There is clear evidence that the consumption of soft drinks and carbonated beverages as well as fast food are related to the development of obesity in children (for a review see Papoutsi et al., 2013). While there are recurrent calls for stricter government regulation (Mudd, 2013)—such as a ban of advertisement of fast food targeting children (Andreyeva, Kelly, \& Harris, 2011), a tax on sugar (Brownell et al., 2009), or stricter food labelling requirements (Hieke \& Taylor, 
2012) - many regulatory approaches to obesity are based on voluntary schemes in cooperation with the food industry (Sisnowski, Handsley, \& Street, 2015; Vallgårda, 2015b). In the UK, the country with one of the highest obesity rates in Europe, the government has adopted a wide range of policy measures, albeit mainly focused on consumer choice and collaborative approaches with industry (Jebb, Aveyard, \& Hawkes, 2013; Vallgårda, 2015a).

Obesity has received strong interest as an issue in need of public policy and has become the subject of extensive public discourse and media attention. Consequently, obesity has been characterised as a 'widely salient issue' by Bonardi and Keim (2005). Widely salient issues are issues that have gained widespread public interest and are regularly covered in the public policy discourse, as opposed to 'narrowly salient issues' that are only advocated by specialised groups outside the public discourse. Due to this public exposure, once issues have become widely salient, it is more difficult for companies to advance their particular interest around the issue because doing so might lead to public backlash (Bonardi \& Keim, 2005).

Obesity as a social-business tension. The obesity pandemic has resulted in increasing pressure on the food and beverage industry (including food retailers and restaurant chains), as it has been identified as one of the major drivers behind a range of diseases (Moodie et al., 2013; Schrempf, 2014; Stuckler et al., 2012; Stuckler \& Nestle, 2012). Food and beverage companies have been called upon to substantively change their business practices to address obesity, e.g. by refraining from advertising HFHS foods to children (Harris, LoDolce, \& Schwartz, 2015), through product reformulation (Sacks et al., 2015), or by being transparent to consumers (Swinburn et al., 2015). Food and beverage companies have also been criticised (The PLoS Medicine Editors, 2012; Wansink \& Huckabee, 2005) for lobbying against obesity policies (Mialon, Swinburn, \& Sacks, 2015; Nixon, Mejia, Cheyne, \& Dorfman, 2015a) and for confusing the public over the sources of obesity (Karnani et al., 2014; Peloza, Ye, \& Montford, 2015). 
The global obesity pandemic constitutes a social-business tension for food and beverage companies (Iivonen, 2018). For many food and beverage companies processed HFHS foods and drinks represent high-margin and best-selling products. Companies try to protect their core business against public interventions and regulation. At the same time, stakeholder pressures that bring attention to obesity push for change because aggressive marketing of processed HFHS food conflicts with the fight against obesity. Addressing obesity requires a significant reduction of HFHS food consumption and thus jeopardises current business practices. Mounting regulatory and stakeholder pressure to tackle obesity challenges the core business of many food companies (Wansink \& Huckabee, 2005). However, fundamentally changing their strategy to address obesity might put companies' commercial success at risk. As a result, food and beverage companies are torn between conflicting but interrelated demands from commercial objectives and the need to respond to stakeholder pressures for fundamental change for addressing obesity (Iivonen, 2018; Karnani et al., 2014; Kleiman, Ng, \& Popkin, 2012). Thus, tackling obesity is at the same time contradictory to, and interrelated with, the core business of many food and beverage companies and therefore constitutes a strategic tension.

What aggravates this tension is the fact that obesity is a widely salient issue, which means that the main pressure to address obesity stems from various stakeholders from the nonmarket sphere such as NGOs and regulators. Despite growing niche market segments for healthier food, strong market signals for a demand for unhealthy food products persist. Reformulating HFHS products to respond to public pressure or regulation not only poses technological challenges, but also clashes with consumer habits and preferences for taste and texture (Raghunathan, Naylor, \& Hoyer, 2006). Removing HFHS products altogether entails the risk of considerable financial losses in the short run and uncertainty about financial performance in the long run. The social-business tension between the commercial success of 
HFHS products and the public pressure to address obesity puts many food producers' core business at risk because customers might not be willing to accept changes to the products they are used to consuming on a daily basis. To illustrate, in 2012, in response to straggling financial performance and investor pressure, PepsiCo’s CEO, Indra Nooyi, had to roll back her previously launched "good for you" and "better for you" initiatives that aimed at promoting healthier food and drink options. Moreover, she boosted the company's marketing for traditional sugary drinks and salty snacks (Estrel \& Bauerlein, 2011; Simon, 2012a). As another example, Tesco's announcement to remove the sugary drink Ribena from its shelves spurred a public outcry and ferocious protests among consumers, known as Ribena-gate. ${ }^{2}$

\section{Obesity as a Strategic Tension}

The literature on organisational tensions defines strategic tensions as competing, yet interrelated demands that are 'particularly prevalent, challenging and consequential to an organization's fate' (Smith, 2014: 1593). The social-business tension fuelled by the obesity crisis represents such a strategic tension as it reflects a situation in which pressures from the external environment jeopardise the core business and commercial direction of food and drink companies.

Responses to strategic tensions. Several authors have addressed organisational responses to strategic tensions around social issues (Hahn, Figge, Pinkse, \& Preuss, 2018; Hahn et al., 2015; Hahn et al., 2014; Van der Byl \& Slawinski, 2015). This literature argues that, due to the plurality of potentially inconsistent social demands of various influential stakeholders, social issues and commercial goals are simultaneously contradictory and interrelated (Berger, Cunningham, \& Drumwright, 2007; Smith, Gonin, \& Besharov, 2013). However, not all tensions around social issues are strategic. Tensions only qualify as strategic if the issue at hand affects a company's core business and competitive advantage (Iivonen, 2018).

\footnotetext{
${ }^{2}$ The Grocer, Ribena-gate reveals consumer dislike of 'choice editing', 31 July 2015.
} 
Interestingly, the literature on organisational tensions maintains a rather strict dichotomy between, on the one hand, a view that rejecting tensions leads to defensive responses and undesirable outcomes, and, on the other hand, that engaging tensions leads to constructive responses and desirable outcomes. Organisations might respond defensively to strategic tensions and circumvent them (Jarzabkowski, Lê, \& Van de Ven, 2013), due to the anxiety and discomfort they generate (Lewis, 2000; Smith \& Berg, 1987). Such defensive responses spur vicious cycles (Lüscher \& Lewis, 2008; Sundaramurthy \& Lewis, 2003), leading to paralysis and stuckness (Lüscher \& Lewis, 2008). By contrast, organisations might respond constructively when tensions are seen 'as an invitation to act' (Beech, Burns, de Caestecker, MacIntosh, \& MacLean, 2004: 1327). Smith and Lewis (2011) argue that constructive responses where the 'awareness of tensions [triggers] a management strategy of acceptance rather than defensiveness' (p. 391) depend on the ability to embrace rather than avoid tensions. When organisations embrace tensions, they maintain a 'productive tension' between opposing elements (Battilana, Sengul, Pache, \& Model, 2015). Such constructive responses have been shown to result in virtuous cycles (Smith \& Lewis, 2011) and positive outcomes such as creativity (Miron-Spektor, Gino, \& Argote, 2011) and innovativeness (Gebert, Boerner, \& Kearney, 2010). With regard to tensions around social issues, it has been suggested that actively engaging tensions will be beneficial both for organisational and social outcomes (Hahn, Pinkse, Preuss, \& Figge, 2016; Smith \& Lewis, 2011).

Responses of food and beverage companies. Scholars investigating how food and drink companies respond to obesity have identified similar responses to the ones in other controversial industries (Simon, 2012b), such as denial of adverse effects, lobbying, funding counterfactual evidence, emphasizing the importance of free consumer choice and consumer responsibility (Iivonen, 2018), and adopting social responsibility measures to safeguard legitimacy (Du \& Vieira, 2012). Companies have repeatedly tried to portray themselves as 
part of the solution to the obesity crisis (Darmon, Fitzpatrick, \& Bronstein, 2008; Nixon et al., 2015b). They claim to offer smaller portion sizes or supposedly healthier, low-calorific products, provide labels with nutritional information (Wansink \& Huckabee, 2005), and revise their marketing and advertisement policies (Harris et al., 2015). They also promote physical activity as the solution to balance the consumption of HSHF food and drinks (Karnani et al., 2014). The industry has also tried to avoid and pre-empt hard regulation by taking part in voluntary schemes and public-private-partnerships (Fulponi, 2006).

Overall, while acting on obesity with drastic measures would challenge the core business of food companies (Brownell \& Warner, 2009), ignoring or denying obesity and the related strategic tension is not an option either. With widely salient issues, companies' strategic options to keep control over their strategic direction are limited due to the broad public attention as ignoring or denying the issue would hurt their credibility (Bonardi \& Keim, 2005). Moreover, since the pressure to address obesity is coming from the non-market sphere, the focus of the response is aimed at influencing the public policy debate about the issue. To maintain or regain autonomy over their strategic direction (Bonardi \& Keim, 2005), companies actively engage in the policy debate, in addition to or instead of measures to change their offerings, and thus develop a discursive response to the social-business tension. To what extent food companies are expected or required to substantively change their strategy and offerings in response to the obesity crisis is thus discursively negotiated in the public debate (Calton \& Payne, 2003; Joutsenvirta, 2011; Scherer \& Palazzo, 2011).

Extant studies addressing the food and beverage industry's response to the obesity crisis remain rather descriptive. At the same time, the literature on organisational responses to social issues particularly focuses on discursive tactics as the main mechanism companies use to address social issues such as obesity (Oliver, 1991). To the best of our knowledge, Iivonen's (2018) single case study is the only empirical study that analyses corporate 
responses that focuses on strategic tensions around obesity. She found that companies employed defensive responses even when they accepted the strategic tension around obesity. The mechanisms underlying organisational responses to strategic tensions might be more complex than the simple rejection-defensiveness versus acceptance-constructiveness dichotomy that dominates the literature. In this paper, we therefore ask: How do companies respond to strategic tensions between their core business and widely salient social issues in their engagement in the public discourse? Taking food and drink companies' discursive responses to the public debate around obesity as the starting point, the purpose is to identify the underlying mechanisms of corporate discursive responses to strategic tensions around widely salient social issues.

\section{METHODS}

\section{Context and Data Collection}

We explore the mechanisms that companies use to discursively address strategic tensions around widely salient social issues focussing on the example of obesity. Obesity is a social issue that has become widely salient for companies only fairly recently. In the transition phase from a narrowly salient to a widely salient social issue (Bonardi \& Keim, 2005), companies feel that the issue is still contested and public attention might either dissipate or further intensify and disrupt the status quo in an industry (Mahon \& Waddock, 1992). In this transitional phase, companies have the opportunity to influence the direction of the public debate. However, due to the issue's increasing salience, the debate is no longer just one between a company and one pressure group, as would be the case for a narrowly salient issue, but it is now facing broad regulatory and social movement pressure. As a consequence, companies cannot overtly reject the issue or try to discredit the legitimacy of the one pressure group but have to strategically orchestrate their opposition vis-à-vis a broad set of stakeholders (Bonardi \& Keim, 2005). 
To capture how companies deal with strategic tensions around widely salient social issues, we conducted a qualitative analysis (Ariño, LeBaron, \& Milliken, 2016) of food and drink companies' discursive responses to stakeholder pressure on obesity in the media. We chose the UK as empirical context because it is the country with one of the highest obesity rates in Europe, which has led to an active public debate. While the UK obesity debate has a longer history, we took 2010 as starting point for our analysis, because this is when the UK government decided to take a more active stance on obesity. A key event in the official policy of the UK government on public health was the publication of the 'Policy paper 2010 to 2015 government policy: obesity and healthy eating'. The public debate was further spurred by a Foresight report 'Tackling Obesities: Future Choices' which led to a first policy white paper published 30 November 2010: 'Healthy lives, healthy people: our strategy for public health in England'. The UK government's changing stance has led to increased pressure on the industry from social movements (i.e., not only activism from pressure groups but also from experts from the medical field) to tackle obesity and to a more active debate in the popular press. To capture this debate and the business involvement in it, we collected data from three national newspapers (The Financial Times, The Guardian and The Telegraph) that represent the spectrum of the political landscape and three UK-based trade journals that cover the food, beverage, and retailing sectors (The Grocer, Food Manufacture, Just-Food) for the period 2010-2015.

We consulted these newspapers and trade journals through the Factiva database. We used the search terms 'obesity' and 'obese' to find the relevant articles. However, as this was leading to much irrelevant data, such as general advice on healthy eating, we narrowed down the number of articles by scanning the abstracts in Factiva. We only selected those articles dealing with the political debate on obesity and featured the opinion of business, the government, NGOs and (medical) experts. While we collected articles presenting different 
stakeholder perspectives, for the purpose of this paper we narrowed down the data by focusing only on articles that contained the business perspective of food and drink industry representatives (see Table 1). Building on earlier work on food companies' role in the debate around obesity (Kolk, Hsin-Hsuan Meg, \& Van Dolen, 2012; Mialon et al., 2015), we sought to uncover how companies portray and influence the tensions between fighting obesity and marketing processed HFHS food and drinks. As unit of analysis we took excerpts that contained statements with regard to obesity and how food and drink companies view the issue. We specifically looked for statements that referred to the strategic tension between companies' core business and obesity and explained how they were approaching this strategic tension. These excerpts captured statements of company representatives, including spokespersons or CEOs, or of industry associations speaking on behalf of companies from the industry.

**** Insert Table 1 about here ***

\section{Data Analysis}

We used an inductive approach to uncover patterns from the data of how companies engage in the public debate around obesity and discursively respond to the inherent strategic tension, to make sense of these patterns, and to identify the underlying mechanisms that explain the response patterns by linking them to insights from the extant literature on responses to institutional pressure (Maguire \& Hardy, 2009; Oliver, 1991) and the literature on organisational tensions (Putnam, Fairhurst, \& Banghart, 2016; Schad, Lewis, Raisch, \& Smith, 2016). To code the data, we used NVivo 11. In a first round of coding, all three authors independently coded the same newspaper and trade journal articles from a two-month period to identify patterns in food and beverage companies' approach to the strategic tension around obesity. The emerging codes were then discussed and consolidated to come up with a common coding structure. Subsequently, the entire data set was divided among the three 
authors and coded collaboratively, using the same emerging coding structure. As soon as new codes appeared the coding structure was updated until a point of saturation was reached. We coded for different patterns that emerged from the data in terms of how food and beverage companies discursively constructed the strategic tension between their business and obesity in the public debate.

In our coding, we first tried to make sense of the arguments that companies used to when engaging in the public debate on obesity. We noticed that companies were engaging in the public debate either directly through their own spokespersons or indirectly by voice of their industry associations' spokespersons. ${ }^{3}$ Accordingly, we identified statements where spokespersons from companies and industry associations were countering criticism of their core business and specifically referred to the tensions that they experienced in doing so. Based on the principle in journalism of audi alteram partem — listen to the other side - such statements often aimed to address a specific tension arising from the announcement of a new policy measure, such as a nutrition tax, that might threaten company sales, or a new report with evidence on obesity that calls into question the health impact of the fast food business.

The data showed that, generally, when a more critical stance was taken towards the policy measure or report, spokespersons from industry associations such as the Food and Drink Federation (FDF) were used as the main voice but a few highly visible companies, in particular, like Kellogg's, Coca-Cola, McDonald's, and Nestlé, did not shy away from speaking critically on their own behalf. Nonetheless, it was more common for companies to unilaterally engage in the debate, often in an unsolicited way, to showcase their more proactive measures. In analysing the statements by companies and industry associations, we

\footnotetext{
${ }^{3}$ In the parts of the data that we coded, we found a total of 89 companies engaging in the public debate and a total of 37 industry associations. While many companies and industry associations were featuring in the data, the analysis showed a much stronger involvement of large multinationals such as Coca-Cola, Unilever, Nestlé, Mondelez, AB Sugar and Tesco, as well as the following industry associations: Food and Drink Federation, British Soft Drinks Association and British Retail Consortium.
} 
focused on finding general industry trends instead of company-specific responses. Overall, companies were well aligned in their engagement in the public debate which does not mean that some companies were having a dissenting voice on some topics.

We initially uncovered various response patterns, which included, in no particular order, shifting, diluting, deactivating, destabilising, appropriating and backgrounding. These labels were derived from our own interpretation of how companies positioned themselves against allegations that their core business was related to rising obesity levels. Companies would not exclusively rely on one response pattern but use a combination, depending on the specific topic discussed. At first, the response patterns were fairly unorganised. To conceptually make sense of the variation, we tried to uncover the underlying mechanisms that explain the different response patterns.

To uncover these mechanisms, we first went back to the literature that deals with organisational tactics to deal with institutional pressures (Oliver, 1991). Theoretically, the emerging response patterns captured various discursive tactics as proposed by organisational discourse theory (Maguire \& Hardy, 2009; Phillips, Lawrence, \& Hardy, 2004). As Maguire and Hardy (2009, p. 149) explain, '[o]rganizational discourse theory tells us that texts are integral to the creation of meaning, but that they do not function individually or independently; instead, meaning is created from collections of texts - or discourses - that evolve from the ongoing production, distribution, and consumption of individual texts.' In view of the widely salient nature of obesity and the food companies' attempt to maintain autonomy over their strategic direction, our response patterns showed various discursive tactics that spokespersons used to give meaning to obesity in relation to their business.

Based on this analysis, we detected the choice of discursive tactics as the first underlying mechanism of food companies' response to strategic tensions around obesity in the public debate. This mechanism confirms earlier studies on purposeful efforts of organisations to 
control the public discourse around contested issues (e.g. Maguire \& Hardy, 2009). Similar to the response strategies to institutional pressures Oliver (1991) proposed, we found that representatives from the food and drink industry used a set of discursive tactics ranging from more adversarial to more accommodating ones. We grouped the discursive tactics companies employed into three categories along this continuum — questioning, tying up, and capturingto distinguish between discursive responses to obesity tensions. On the more adversarial end, companies were trying to convey the message that they were not playing a big role in the obesity problem and, on the more accommodative end, companies were portraying themselves as part of the solution. At the beginning of the findings section, we explain the three discursive tactics companies employed in more detail.

However, the mechanism of the choice of discursive tactics did not allow us to explain the full variation of companies' response patterns. Following our focus on organisational tensions, we went back to the literature on the debate around strategic tensions and their emergence (Schad et al., 2016). We detected different ways of dealing with strategic tensions in the response patterns that reflected the constitutive approach to tensions (Putnam et al., 2016). According to the constitutive approach, tensions are socially and discursively constructed. As Jarzabkowski and Lê (2017) found, the way actors discursively construct tensions is innately linked to how they process and respond to tensions. We returned to the data to examine how companies constructed the tension around obesity and identified a second mechanism - construction of tension - that captures how companies discursively constructed the tension between obesity and their core business. Through this second mechanism companies construct the strategic tension in such a way to either neutralise or attenuate the tension. Companies' public discourse on obesity was linked to and determined by the construction of the underlying strategic tension.

Once we had uncovered these two mechanisms and juxtaposed them, we could make 
better sense of the patterns that we observed. This analytical approach towards understanding the patterns led us to reinterpret some of the statements from the data. Consequently, we went through all coded excerpts again to make sure that they were coded as part of the correct pattern. For each pattern, we assessed the discursive tactic chosen and the specific construction of the tension. In this final round of coding, each author was coding a different part of the data compared to the previous round with the aim to further harmonise our coding. In the next section, we present our findings by showing how the two underlying mechanisms - choice of discursive tactics and construction of tension - together explain how food and drink companies deal with strategic tensions between obesity and their core business.

\section{FINDINGS}

\section{Discursive Tactics and Construction of Tensions}

Between 2010 and 2015, food and drink companies and their industry associations were actively involved in the public debate on obesity in the UK. As our findings show, most food and drink companies acknowledged the tension between obesity and their core business but also tried to put it into perspective, as the following quote by the International Business Leaders Forum illustrates: 'The IBLF fully acknowledges the real commercial tensions companies face between growing sales volumes and addressing chronic health issues. However, our experience is that responsible businesses are willing and able to engage voluntarily with government and society at large in order to innovate and adapt their business models and thereby play their part in making our world more sustainable. ${ }^{4}$ Even if food and drink companies acknowledged the strategic tension around obesity, our data shows that companies' engagements in the obesity debate have been rather ambiguous. Companies were actively altering existing and creating new tensions to obfuscate the underlying strategic

\footnotetext{
${ }^{4}$ The Guardian, Business interests and the fight against obesity, 12 July 2010.
} 
tension between obesity and their core business. As mentioned above, we identified two mechanisms companies used in this context that together explained the six distinct responses patterns emerging from the data.

The first mechanism is the choice of discursive tactics. We identified three discursive tactics that we refer to as questioning, tying up and capturing. Questioning weakens the perceived relevance of the strategic tension for food and drink companies. Through tying up companies connect the social issue, or an intervention to address the issue, in competing tensions. With capturing companies marginalise the strategic tension by portraying themselves as part of the solution. All three discursive tactics aim to protect companies' core business by reducing the threat obesity poses to them. The second mechanism is the construction of tensions. We identified two ways in which companies discursively construct tensions: deconstruction and reconstruction. Through deconstruction, companies seek to neutralise the strategic tension and the direct link between obesity and their core business (as represented by the crossed-out tensions on the left-hand side of Figure 1). With reconstruction, companies try to weaken the strategic tension by altering the nature of the link between obesity and their core business (as depicted by the alterations to the strategic tension in red on the right-hand side of Figure 1). Hence, while reconstruction leaves the original tension intact, deconstruction alters the direct link to obesity.

Together, these two mechanisms provide an explanation for the six response patterns we identified. Figure 1 shows the framework that emerged from our data and categorises how the two mechanisms result in six different response patterns. In the following, we explain each pattern separately, highlighting how the underlying mechanisms of choice of discursive tactics and construction of tensions allow companies to protect their business against stakeholder pressure in the public debate (see Table 2 for a summary of the response patterns and exemplary quotes). 
**** Insert Figure 1 and Table 2 about here ****

\section{Response Patterns}

Deactivating - challenging the link to obesity. Deactivating refers to a response pattern whereby companies challenge the underlying scientific evidence on the link between HFHS foods and obesity by highlighting or supporting studies that provide counterfactual evidence. They deconstruct the strategic tension as they discursively question the underlying evidence on the link between HFHS foods and obesity (see Figure 1). The industry association for British sugar producers - Sugar Nutrition UK -, for example, criticised a peer-reviewed study associating sugar with diabetes by making the rhetorical claim that there is no causal relation as 'British consumption of sugar had declined by $6 \%$ in the past decade, during which time the prevalence of diabetes had doubled.' ${ }^{5}$ Glenys Jones, the association's nutrition manager, was quoted as saying: 'Expert reviews of the scientific evidence are clear and in agreement sugar does not cause diabetes. ${ }^{6}$ By questioning this link, companies deconstruct the tension around obesity to refute there being a tension in the first place.

Companies questioned the science by referring to specific studies that disprove the accusations held against food and drink companies or shed a different light on the tension. In the data, questioning the link between HFHS foods and obesity was particularly reflected in statements from industry associations. Given the widely salient nature of obesity, for companies to directly question this link is precarious as it could damage their reputation which likely explains why they instead use industry associations for this purpose or fund dissenting scientific studies (see below). The only company found to be directly questioning the science was Kellogg's which highlighted on their website the results of a study that raised doubts about the relation between sugar consumption and obesity (see Table 2). While the study was based on credible research, the UK advertising watchdog ruled Kellogg's statement

\footnotetext{
${ }^{5}$ The Guardian, Sugar blamed for global surge in type 2 diabetes cases. 28 February 2013.

${ }^{6}$ The Guardian, Sugar blamed for global surge in type 2 diabetes cases. 28 February 2013.
} 
as misleading because the company failed to point out that there were many studies

confirming this relation as well. ${ }^{7}$ Companies also accused their critics of using rhetorical arguments. The director general of the Food and Drink Federation (FDF), Ian Wright, argued for example:

The most thorough scientific review of carbohydrates and health carried out in recent years should leave people in no doubt that sugars can be enjoyed safely as part of a varied and balanced diet. Sensationalist commentaries on this everyday ingredient that are not based in science should now be relegated to the past. Demonising any one ingredient in the obesity debate isn't helpful. ${ }^{8}$

Another way for companies to deactivate the strategic tension is by funding scientific studies that question the link between HFHS foods and obesity. In our data, especially CocaCola is accused of funding research that weight loss can also be achieved by more exercise instead of consuming less or research that finds no association between sugary drinks and obesity. ${ }^{9}$ A medical study from 2013 found that 'reviews of the effects of sugary drinks on obesity with industry funding were five times more likely to conclude that there was no link than those without industry funding. ${ }^{10}$ Companies leverage the importance that the public attaches to scientific evidence by presenting their own evidence to counterbalance scientific evidence brought into play by their critics. By highlighting or supporting studies that provide counterfactual evidence, companies deconstruct the strategic tension around obesity. By discursively questioning the link between their products and obesity in challenging the underlying scientific evidence, companies seek to deconstruct the tension, so it will no longer be strategic and no longer challenges their business.

Diluting - finding more reasons for obesity. Diluting refers to a response pattern whereby companies highlight alternative or additional factors that contribute to obesity to

\footnotetext{
${ }^{7}$ Just-Food, Watchdog rules Kellogg sugar claim “misleading”. 9 March 2012.

${ }^{8}$ Just-Food, Sugar consumption should be halved, UK panel urges, 19 July 2015.

${ }^{9}$ The Guardian, Coca-Cola says its drinks don't cause obesity. Science says otherwise, 17 August 2015.

${ }^{10}$ The Telegraph, Government obesity adviser Susan Jebb took research funding from Coca-Cola, 12 February 2015.
} 
discursively question whether business activities represent the main cause for obesity (see Figure 1). Instead of neutralising the tension by claiming that there is no link between their products and obesity, with dilution companies question this link and reconstruct the strategic tension instead. They emphasize other factors contributing to obesity and thus dilute the unequivocal link between obesity and their core business. A Kellogg's spokesperson argued, for example: 'When you look at the facts you'll see that our cereals only account for six per cent of sugar in the nation's diet - way less than something like fruit juice and toast with jam. ${ }^{11}$ In connection with downplaying the contribution of their products to the overall, complex problem, especially the industry associations British Soft Drinks Association and FDF have used the argument for years that sugar is being demonised in the debate. As the FDF director stated:

Obesity is a complex problem which cannot be reduced to the demonisation of one ingredient, nor can it be right that an everyday ingredient such as sugar is characterised as a poison. ${ }^{12}$

Individual companies have used this argument as well, including Britvic, Unilever and $A B$ Sugar, the latter of which stated that 'focusing on one type of ingredient alone is not going to solve the issue. We believe people need to look at diet within the context of lifestyle, with the starting point being calories (energy) in and calories (energy) out.' ${ }^{13}$

Diluting still relies on the discursive tactic of questioning but works in a subtler way than deactivating; diluting reconstructs the tension by highlighting other factors leading to obesity. Companies do not negate the tension between HFHS foods and obesity but reconstruct it to convince the public that the role of food and drink companies is not unequivocal. The contribution of the food and drink companies to obesity is diluted to the degree that reconstructing the tension results in a perception that food and drink companies only play a

\footnotetext{
${ }^{11}$ Just-Food, UK: DoH rejects Labour calls for sugar regulation, 22 June 2014.

12 Just-Food, FDF - Health chief wrong to "demonise" sugar, 6 June 2015.

${ }^{13}$ The Guardian, Sugar should be no more than 5\% of daily calories, say nutrition experts, 17 July 2015.
} 
minor role and other causes for obesity are at least as important. As this response is relatively nuanced, we found that companies were comfortable with using their own voice in the debate but also continued to rely on industry associations. With diluting companies thus try to attenuate stakeholder pressure by discursively questioning that their activities represent the main cause for obesity. As Figure 1 shows, while dilution might not remove the tension between food and drink companies' core business and obesity, in arguing for other causes as well, it helps keeping the core of the business intact.

Shifting - pointing to others. Shifting represents a response pattern where companies shift the responsibility for obesity away from their business onto consumers by pointing at the importance of a healthy lifestyle, physical exercise and the 'energy balance'. Companies discursively tie up another party in a tension with obesity and thereby deconstruct the strategic tension that refers to their own business activities. In their statements, companies aim to shift the responsibility from themselves to other actors. In the data, it was predominantly highly-scrutinized companies such as Coca-Cola, McDonald's, Nestlé, and Kellogg's that used this approach in response to criticism. The industry associations further supported these companies by reiterating that consumers are also responsible for tackling obesity, if not more. Shifting is a form of deconstruction because by discursively tying up others into the responsibility to tackle obesity in food companies' stead, they try to neutralise the link between their core business and obesity (see Figure 1).

Consumers were the most common party that companies tried to tie up into the tensions around obesity. In their statements, company and industry spokespersons repeatedly shifted the attention to consumers and their responsibility for a healthy lifestyle in general and a healthy diet in particular. By blaming people's lifestyles, the attention is deflected from the role of food and drink companies. A prominent, recurring example was food companies trying to shift responsibility to parents with regard to their children's fast food consumption. Jot 
Condie, president and chief executive of the California Restaurant Association, stated, for example, that ' $[\mathrm{u}]$ ltimately, parents decide what their children eat and whether a meal includes a toy or not - that is the role of a parent. ${ }^{, 14}$ Similarly, on the issue of TV advertising during peak children's viewing times the chief executive of the Australian Food and Grocery Council (AFGC), Geoffrey Annison, argued that 'children's exposure during this time is a family choice and it lies with the family to determine how different products advertised fall within their diet.' ${ }^{15}$ Putting others' responsibility to the fore while lowering food companies' responsibility was also exemplified by McDonald's. By saying that 'Our customers are competent and capable of making decisions' ${ }^{16}$ and 'if we were to close our doors of all of the McDonald's tomorrow, the obesity problem would not go away' ${ }^{17}$, McDonald's put the responsibility of customers central in an attempt to reduce its own responsibility and deconstructs the tension by stating that closing down would not make a difference.

Another prominent example for how companies use tying up to shift the strategic tension is the discourse around 'energy balance'. Companies repeatedly claimed that all calories are the same. All consumers have to do to avoid obesity is to make sure that they find a balance between the calories they consume and the calories they burn off. As the R\&D chief of the B2B cocoa and chocolate producer, Barry Callebaut, stated:

You can't make food responsible for people getting fat. It's net calorie intake that makes you fat. If you don't get off your butt and move a little, eat whatever you like but you will get fat. The balance needs to be there. ${ }^{18}$

In response to the recommendation to let sugar not be more than $5 \%$ of daily calories, $\mathrm{AB}$ Sugar argued that 'focusing on one type of ingredient alone is not going to solve the issue. We believe people need to look at diet within the context of lifestyle, with the starting point being

\footnotetext{
${ }^{14}$ Financial Times, California county seeks to ban toys at fast-food chains, 12 May 2010.

15 Just-Food, Focus: Australian suppliers still under scrutiny on children's ads. 25 May 2012.

${ }^{16}$ Financial Times, McDonald's sued over toys with meals, 16 December 2010.

17 The Telegraph Online, McDonald's head chef says no products are unhealthy; McDonald's head chef has stated he does not believe any of the food served by the fast food chain is unhealthy, 12 June 2012.

18 Just-Food, The just-food interview - Hans Vriens, Barry Callebaut, 15 March 2012.
} 
calories (energy) in and calories (energy) out.' ${ }^{19}$

Based on the energy balance discourse, companies promoted physical exercise as a way to divert the attention away from HSHF food and drinks and to shift the strategic tension onto consumers. Coca-Cola promoted exercise by sponsoring sports events such as the London 2012 Olympics $^{20}$, funding advocacy groups like the Global Energy Balance Network that published research blaming a lack of exercise for obesity ${ }^{21}$, and broadcasting ads focusing on this theme. In one ad, Coca-Cola showed how activities such as walking the dog and dancing would help 'burning off the "140 happy calories" in a can of Coca-Cola.' 22 Closely related to the energy balance discourse is the argument that even though some food might be less healthy, it can still be part of a healthy or balanced diet. As Nestlé's CEO, Mr. Bulcke, argued, 'there is no such thing as bad foods, only bad diets [...] it is down to individuals to limit their consumption of chocolate and other treats. ${ }^{23}$ In a similar fashion, Pizza Hut used this argument to defend its launch of a 3,000-calorie pizza:

Pizza Hut insisted the "delicious limited edition" cheeseburger pizza was part of a wide ranging menu which also included pastas and salads. In a statement the chain said: "We are committed to producing a wide range of fresh, high quality food which can be enjoyed as part of a balanced diet." 24

In its purest form, with shifting companies portray a situation where they have almost no agency but that the onus is on consumer choice instead. Along these lines, the FDF, for example, argues that it is impossible to regulate consumer choice: 'You can't legislate for human behavior. In the end the consumer will decide. ${ }^{25}$ By shifting responsibility to the consumer, using various discourses related to the responsibility of parents, energy balance, and healthy diets, companies try to deconstruct the tension. They seek to shift the tension

\footnotetext{
${ }^{19}$ The Guardian, Sugar should be no more than 5\% of daily calories, say nutrition experts, 17 July 2015 .

${ }^{20}$ The Grocer, CSR obesity strategies in line for the 'shock doc' treatment, 2 March 2013.

${ }^{21}$ The Guardian, Coca-Cola says its drinks don't cause obesity. Science says otherwise, 17 August 2015.

${ }^{22}$ The Daily Telegraph, Coke campaign tackles the issue of US obesity, 15 January 2013.

${ }^{23}$ Financial Times, Nestlé in over-regulation' warning, 22 June 2012.

${ }^{24}$ The Telegraph, Pizza Hut panned for near 3,000 calorie 'cheeseburger' pizza, 17 September 2013.

25 The Grocer, Ian Wright: Big interview with FDF's new director general, 4 July 2015.
} 
around obesity away from their business toward the consumer, arguing that it is actually the consumer who decides. The more the public debate becomes one about consumer responsibility, the more tying up of other actors allows companies to neutralise the strategic tension around their own core business.

Destabilising - when no solution is good enough. We also identified a response pattern where companies introduce a competing tension to destabilise interventions or proposed measures to tackle obesity by highlighting the unintended consequences or ineffectiveness of such measures. Destabilising draws on the discursive tactic of tying up to reconstruct the strategic tension by introducing a competing tension that destabilises the perceived effectiveness of proposed interventions or measures (see Figure 1). While the original tension persists, interventions or measures that pose a risk to companies' core business are weakened, making them seem less effective. Destabilising occurs for instance when food companies point to unintended consequences or the ineffectiveness of policy measures such as specialised taxes. Compulsory labelling schemes were portrayed as being simplistic, leading to confusion among consumers because there are rivalling schemes, and having the government act as 'food police' or 'nanny state'. ${ }^{26}$ Companies also argued that a unilateral UK approach would lead to extra costs and further confuse the consumer. ${ }^{27}$

Food and drink companies, predominantly by voice of their industry associations, tried to destabilise the introduction of a nutrition tax such as a sugar or fat tax. The creation of competing tensions was often based on discursively tying up the proposed tax with undesirable consequences of the tax. As a result, companies reconstructed tensions around interventions to address obesity in order to portray the intervention as problematic and complex. Industry associations invoked a discourse around a health-versus-wealth tension with regard to suggested nutrition taxes:

\footnotetext{
${ }^{26}$ Financial Times, Nestlé in 'over-regulation' warning, 22 June 2012.

27 Just-Food, Retailers slam FSA's labelling plans, 7 March 2010.
} 
"All the economic data out there is very theoretical," says Shane Dempsey, head of consumer foods at Food and Drink Industry Ireland (FDII). "At this point taxes like this haven't been proven to work. There is no proof that these taxes actually improve the obesity situation or improve health. They affect wealth more than health." Dempsey urges the government to look at "other more pragmatic solutions" rather than a policy which could potentially "damage jobs, growth and competitiveness" in the food sector. He says that the Danish example has proven that nutrient taxes "have bigger wealth impacts than health impacts", adding that fat taxes are "too blunt an instrument" and on the health argument alone "aren't proven to work. ${ }^{28}$

Next to highlighting tensions between nutrition taxes and companies' jobs, growth, and competitiveness (as the quote above highlights), ${ }^{29}$ companies engaged in discourses that portrayed the introduction of a nutrition tax as a means to generate additional tax revenue to make up for budget deficits. ${ }^{30}$ The destabilising effect of these competing tensions tends to be reinforced by referring to a lack of evidence that a nutrition tax is actually effective in tackling obesity. In this context, the case of Denmark where a tax on saturated fats, introduced in 2011 but abolished in early 2013, was mentioned repeatedly because it was argued to lead to negative economic impacts without having any health benefits. ${ }^{31}$ In a similar vein, the British Soft Drinks Association's (BSDA) director general claimed that a sugar tax in Mexico only has had a marginal impact so far in terms of reduced calorie consumption. ${ }^{32}$

To destabilise a nutrition tax further, food and drink companies also engaged in a discourse about regressive effects of such a tax in that it will hit poor households most. The following FDF statement illustrates this 'hitting the poor' discourse: 'Soft drinks are currently taxed at the standard VAT rate of 20 per cent. Any additional taxation of food will hit the poorest families hardest at a time when they can least afford it. ${ }^{33}$ Other grounds on which companies tried to destabilise government interventions was by claiming that such taxes

\footnotetext{
${ }^{28}$ Just-Food, Nutrient taxes: Irish food industry sets out case against nutrient taxes, 31 October 2012.

${ }^{29}$ Just-Food, Nutrient taxes: European moves on nutrient taxes fuel debate. 31 October 2012.

${ }^{30}$ Food Manufacture, Soft drink bosses' bitter view of sugary food tax, 1 April 2012.

${ }^{31}$ The Guardian, Mexico at forefront of war on obesity with junk food tax: President warns that millions of lives are at risk: Country tackles food and drink industry head on, 2 November 2013.

${ }^{32}$ Food Manufacture, Time to play fiscal hard ball?, 1 March 2015.

${ }^{33}$ Financial Times, Whitehall in spin over sugar, 29 January 2013.
} 
would hit ethnic minorities most ${ }^{34}$, hinder voluntary regulation that the industry is already involved in ${ }^{35}$, and lead to a 'bureaucratic nightmare' ${ }^{36}$. By tying up other political issues to the obesity debate, proposed policy measures are portrayed as either not effective or being introduced under false pretences.

Apart from government interventions, companies also tried to destabilise other measures to address obesity, such as calls for product reformulation. Often in the context of launching healthier alternatives, companies directly defended decisions to leave their original, highsugar products unchanged (see Table 2). An industry expert pointed, for example, at the technical difficulties of reformulation by saying: 'it is technically very difficult to reduce [high fat, salt and sugar] levels without seriously affecting taste and texture at the moment'. ${ }^{37}$ Similar arguments were used regarding the high cost of reformulation ${ }^{38}$, the impact on taste ${ }^{39}$ and the impact on customer choice ${ }^{40}$ of reformulation. Casting doubt on the effectiveness or intentions of proposed interventions weakens the idea that the ostensible tension between food and drink companies' core business and obesity can be addressed. With a response pattern of destabilising, companies thus protect themselves from interventions and measures that would challenge their current core business.

Appropriating - look at how we tackle obesity. In a response pattern that we labelled appropriating, companies create a public perception of actively taking part in the fight against obesity by claiming that measures such as product reformulation and 'delivery of choice' contribute to solve the problem. Here, companies combine the discursive pattern of capturing and a deconstruction of the tension. In the data, companies overwhelmingly used their own

\footnotetext{
34 The Daily Telegraph, New York's fizzy drink prohibition falls flat, 12 March 2013.

${ }^{35}$ The Guardian, Burnham calls for legal limits on salt, sugar and fat in food, 9 November 2012.

${ }^{36}$ Just-Food, Danish firms criticise 'fat tax', 7 October 2011.

${ }^{37}$ Food Manufacture, Gluten-free sector would be hit hard by sugar and fat taxes. 1 February 2015.

${ }^{38}$ The Grocer, Reducing the satfat content of the Mars bar took five years and cost $£ 9 \mathrm{~m}$, but I think it will be worth the wait - and the money. 16 January 2010.

${ }^{39}$ Food Manufacture, Bakeries reduce portion sizes to cut obesity levels. 1 September 2014.

${ }^{40}$ Just-Food, Focus: What could be impact of Heinz's stevia ketchup?. 14 September 2014.
} 
voice to show what they have been doing to tackle obesity so as to make sure that they are 'rewarded' for their actions in terms of discursively alleviating public pressure and making the strategic tension go away (see Figure 1). This response of companies portraying themselves as being part of the solution of the obesity problem is ubiquitous. Food and drink companies highlight voluntary measures, such as industry-devised labelling schemes, as their contribution to tackling the obesity crisis. ${ }^{41}$ The UK government has been responsive to such measures, as the main policy instrument used throughout the period under study is the Responsibility Deal as part of which companies make voluntary pledges to reduce sugar, salt and fat. Companies and industry associations repeatedly engaged in discourses that stressed the achievements they have made in cutting back on these ingredients. As an FDF representative stated:

"Our members have voluntarily made such significant progress in reducing trans fat levels in their products that I feel that the proposal to introduce legislation is not justified." 42

As this quote exemplifies, one of the reasons for food and drink companies to adopt selfregulation strategies is to prevent further government interventions that would limit their autonomy over strategic choice.

Interestingly, the data suggests that the pattern of appropriating could also become manifest in companies taking concrete actions to reduce the sugar content of their products or reformulate products in other ways. Many established companies acknowledge that consumer demand is changing, and they want to be part of a changing market and not become obsolete. However, the rationale and the effectiveness of appropriation as a discursive tactic are independent from the degree to which food and drink companies' contributions to addressing obesity are substantive or symbolic. Rather, companies seek to establish a dominant discourse

\footnotetext{
${ }^{41}$ Just-Food, US food companies look to take initiative on kids marketing, 21 July 2011.

42 The Guardian, Doctors demand total ban on 'damaging' trans fats in food: Doctors call for trans fats ban, 18 January 2010.
} 
that creates the impression that they actively tackle the obesity crisis, whether they are serious about this or not, as they seek reward for their actions through increased customer demand or avoidance of new regulation. By capturing the obesity debate, companies deconstruct the strategic tension between obesity and their business as the voluntary measures show that companies solve the conflict which neutralises the strategic tension.

Examples of such forms of impression management can be seen in companies taking part in the Responsibility Deal. To protect their current business, companies including Coca-Cola, Irn-Bru, Nestlé, and Unilever have voluntarily changed some of their products to address obesity, which sometimes gained substantial market share, but left traditional products, of which they sell most, unchanged. Nestlé, for example, reduced calories of the KitKat Chunky bars, but did not change the traditional KitKat bar. Unilever and Coca-Cola started offering low-calorie products but did not change their key products such as the Magnum ice creams and traditional Coke. ${ }^{43}$ McDonald's made a big announcement of its pledge under the Responsibility Deal to introduce calorie labels on their products but refused to sign a pledge to reduce salt in its products. ${ }^{44}$ Voluntary programmes allow companies to be seen as an active partner in solving obesity, but they tend to selectively pick measures for compliance instead of fundamentally changing all product lines. However, adding healthier options to complement the traditional product range can be part of an evolutionary process like the case of Robinsons shows, which 'quietly scrapped its entire original recipe range, which came in a green-lidded bottle'. ${ }^{45}$ The data also suggests that appropriation can take the form of defending market share by proactively taking the lead in product reformulation and change all product lines:

SodaStream is to relaunch and replace its entire product range in July as it joins the war against sugar, which it described as a health "time bomb." The products will typically

\footnotetext{
${ }^{43}$ The Sunday Telegraph, Food firms sidestep pledge on sugar, 1 June 2014.

${ }^{44}$ The Guardian, Don't nudge, regulate: McDonald's new calorie labelling is good PR - but it won't make a dent in the obesity epidemic, 8 September 2011.

${ }^{45}$ The Telegraph, Robinsons discontinues classic squash for sugar-free formula, 3 July 2015.
} 
contain 70\% less sugar than existing lines, and have been stripped of artificial sweetener aspartame to tap consumer demand for more natural products. ${ }^{46}$

Another form of appropriating is the emphasis companies put on choice. Companies either stress that they are 'delivering choice' by offering low-calorie products alongside their traditional products or enabling consumers to make an 'informed choice' through the provision of nutritional information on the packaging. The American Beverage Association used 'delivering choice' as a marketing campaign. ${ }^{47}$ Pepsi also adopted it: 'Delivering choice is fundamental to sustained growth as consumers demand a range of options and refuse to compromise on taste and quality'. ${ }^{48}$ In an attempt to stress its contribution to tackling obesity, Coca-Cola emphasised both choice and the high percentage of low-calorie products in its portfolios: 'If you want to enjoy one of our brands there is a zero-calorie or low-calorie alternative you can choose. As far as Coke is concerned, we have one of the highest levels of zero-calorie products across Europe. So $46 \%$ of our total portfolio is zero calorie, through Zero and Light. ${ }^{49}$ Through appropriating, companies do not simply shift the responsibility on healthy nutrition choices to the consumer but rather portray themselves as actively helping consumers to make better choices to avoid obesity and hence deconstruct the tension by seemingly solving it.

In addition to delivering choice, companies emphasise their role in helping consumers to make an informed choice. Companies predominantly do this by providing nutritional information on their products. Notwithstanding initial resistance, partly due to government intervention, a hybrid between guidelines for daily amount (GDAs) and a traffic lights system had become the norm towards the end of the period under study. Interestingly, Nestle pledged not only to provide nutritional information, but also said it wanted to make "healthier portion

\footnotetext{
46 The Grocer, SodaStream slashes sugar levels to combat obesity 'timebomb', 14 February 2015.

${ }^{47}$ Financial Times, Drinks groups fight back over obesity, 7 May 2012.

${ }^{48}$ The Grocer, Can 'healthy' innovation broaden the appeal of bagged snacks?, 19 May 2012.

${ }^{49}$ Food Manufacture, Green game, 1 July 2012.
} 
choices intuitive for consumers' and would develop portion 'guidance at product level, with product form, pack design, clear illustrations or sometimes with a serving device. ${ }^{50}$

Companies also used changes in portion size to leave the impression of addressing the obesity problem. For example, in an attempt of Mars to comply with a Responsibility Deal pledge to reduce single-serve confectionary products' calories to $250 \mathrm{kcal}$ :

Mars' UK division has announced that further reformulations for its chocolate products are not feasible, and portion sizes are instead being reduced to meet the company's calorie reduction pledge. ${ }^{51}$

Changing the portion size of a product is a response Coca-Cola also employed by introducing a 'slimline' can that contains $250 \mathrm{ml}$ instead of $330 \mathrm{ml}$, marketed as being healthier and more convenient. ${ }^{52} \mathrm{AB}$ Sugar launched a campaign to 'inform and educate people' about ingredients. It said the push would 'debunk myths' and 'provide factual and helpful information' to 'confused consumers' ${ }^{53}$ Again, through such voluntary measures, companies try to be seen as helping consumers address obesity. While it seems far less defensive than deactivating and shifting, appropriating relies on the same underlying mechanism of deconstruction as these responses. Companies try to neutralise the strategic tension around obesity by creating the public perception that there is no conflict between the consumption of their products and obesity. In the case of appropriating this perception is created by sending the message that the industry solves the tension through voluntary measures. However, many voluntary measures that we identified left the traditional products largely unchanged which indicates that companies try to stay in control of their strategic direction and do not want to be driven by public pressure. As the case of Robinsons shows, though, appropriation sometimes represents the first step to a more radical strategic overhaul over time.

\footnotetext{
${ }^{50}$ Just-Food, Nestlé makes EU portion, whole grain commitments, 10 September 2014.

${ }^{51}$ Just-Food, Chocolate and the scrutiny on sugar, 10 March 2014.

${ }^{52}$ The Daily Telegraph, Coca-Cola slim can for healthy drinkers, 6 July 2013.

${ }^{53}$ Just-Food, AB Sugar-backed report calls for action on obesity. 14 October 2014.
} 
Backgrounding - look at all the things we do. The final response pattern that we identified, backgrounding, refers companies putting positive contributions to the fore that address and solve tensions around other social issues, but are unrelated to obesity. This pattern thus combines the discursive tactic of capturing with reconstructing the tension (see Figure 1). We refer to this response as backgrounding because rather than directly addressing the tension between food and drink companies and obesity, companies divert the attention to other social issues, unrelated to obesity (Peloza et al., 2015; Richards, Thomas, Randle, \& Pettigrew, 2015). Through backgrounding, companies seek to portray themselves as being responsive to other social issues in order to protect their business by deemphasising the strategic tension around obesity. They reconstruct the strategic tension between their business and obesity by creating a smokescreen of measures that are furthering social progress, but, when scrutinised more deeply, are not related to the obesity problem.

Backgrounding occurs when companies stress a positive impact that they have on social issues that are only tangentially related or completely unrelated to obesity. Companies capture the obesity debate to emphasise other causes in an attempt to background the strategic tension around obesity. One approach of backgrounding is to promote other health benefits of food products that are not necessarily related to obesity. Over the years, food and drink companies have marketed all kinds of health benefits. ${ }^{54}$ Emphasising such health benefits allows companies to move the unhealthy aspects of their products to the background. Bread producer Hovis, for example, argued that adding sugar to its products is actually beneficial for customers, as it lets them eat more of their healthy bread:

A spokesman for Hovis said: "Sugar is only added to part of our range, and it is only added to counteract the bitterness from the bran. Adding a little sugar means that more people are likely to make the move to wholemeal. This is why we do it." 55

\footnotetext{
${ }^{54}$ The Telegraph, Food labels 'fool us' into thinking products are healthy, 17 June 2014.

55 The Sunday Telegraph, Brown and wholemeal s loaves that contain more harmful sugar than white bread, 23 March 2014.
} 
Nestlé made a similar health claim with regard to its Nesquik product by claiming that 'some of its products already come with health benefits. Its Nesquik drink is inducing more children to drink milk and has been reformulated with 20pc less sugar [...] while a version of Nestlé's bouillon cube sold in Africa comes fortified with iodine. ${ }^{56}$ For Nestlé, pushing health benefits has even been chosen as a new move in their strategy in 2010 by setting up the Nestlé Institute of Health Sciences. By doing research on health benefits, Nestlé aims 'to pioneer a new industry between food and pharma that will develop products to combat diabetes, heart problems and Alzheimer's. ${ }^{57}$ Backgrounding can also be unrelated to health altogether. CocaCola has been criticised for a Super Bowl ad focused on diversity to celebrate a multi-ethnic America to actually push sales of their HFHS products to more vulnerable parts of the population. ${ }^{58}$ By highlighting their contribution to other desirable goals, food companies protect their business by reconstructing the strategic tension around obesity because they discursively capture the public debate and divert the focus on other social issues instead.

\section{DISCUSSION}

Our analysis of food and drink companies' response patterns to the public debate on obesity offers novel insights into the way in which companies discursively respond to strategic tensions around social issues that are widely salient. As our main contribution, we identify the accepting-defensive approach to strategic social-business tensions. Most importantly, we offer a fine-grained understanding of the underlying mechanisms of this accepting-defensive approach and explain the variety of accepting-defensive responses. Our analysis reveals that companies' response patterns rely on the combination of two mechanisms: the choice of discursive tactics and the construction of tensions. Together, these

\footnotetext{
56 The Sunday Telegraph, 'Health is going to be a major dimension in our society. It's a new industry in the making; Paul Bulcke surprised the markets last week when he said Nestlé would be moving into nutrition, 3 October 2010.

${ }^{57}$ Financial Times, Nestlé to take on drugs industry with standalone health business, 28 September 2010.

${ }^{58}$ The Guardian, Coca-Cola's America Is Beautiful ad: why liberals should be upset, 3 February 2014.
} 
two mechanisms represent social mechanisms (Hedström \& Swedberg, 1998) that explain six different defensive response patterns to social issues (see Figure 1). While being defensive, the six response patterns all represent active and purposeful efforts to manage the strategic tension, albeit in a way to protect controversial business practices from the public pressure that companies face on widely salient social issues. These insights contribute to the literature on organisational tensions by highlighting that the acceptance of tensions does not necessarily go hand in hand with constructive responses. Our findings also extend the deliberative approach to CSR (Scherer \& Palazzo, 2007) by highlighting the ambivalence of companies' engagement in the discourse around social issues that not only commits them to tackling the social issue but also provides them an avenue to influence the discourse in their own preferred direction.

\section{The Accepting-Defensive Approach to Widely Salient Issues and its Underlying}

\section{Mechanisms}

In this paper, we investigated how companies deal with strategic tensions between their core business and widely salient social issues. When facing such strategic tensions, the set of responses available to companies are limited (Bonardi \& Keim, 2005). Of the five response strategies to institutional pressures that Oliver (1991) proposed-acquiesce, compromise, avoid, defy, and manipulate — both acquiescing to demands for addressing strategic social issues and defying the social issue are no longer viable because they represent a major threat to a company's core business. Instead, we identified the accepting-defensive approach as a unique way for companies to deal with strategic social-business tensions. The acceptingdefensive approach highlights that accepting strategic tensions around widely salient social issues does not represent a sufficient condition for constructive responses to social-business tensions. Yet, defensive responses are not characterised by a passive avoidance of tensions or a defiance of the social issue either (Oliver, 1991). What makes this approach unique is the 
counterintuitive process of accepting a tension while discursively responding to it in a defensive way.

While there is some evidence on the defensive nature of food and drink companies' responses to strategic tensions (Darmon et al., 2008; Iivonen, 2018; Karnani et al., 2014; Kleiman et al., 2012; Nixon et al., 2015b), the accepting-defensive approach has not yet been identified and discussed in the literature. Based on our analysis, we contend that the accepting-defensive approach consists in purposefully managing strategic tensions with the aim to reduce a company's exposure to the tension to (at least temporarily) avoid vicious cycles and negative consequences and to gain time to prepare for change. One of the main concerns of companies when facing pressure to respond to widely salient social issues is to maintain or regain autonomy over their strategic direction when the options to do so are limited due to the broad public attention (Bonardi \& Keim, 2005). Hence, the defensive nature of most of the responses we found does not stem from a fundamental rejection of the issue of obesity. Rather, the defensiveness mainly referred to safeguarding companies' autonomy with regard to the question how the obesity crisis should be tackled.

We not only identify the accepting-defensive approach to strategic tensions but also offer insights into how its underlying mechanisms can be theorized. As the first mechanism, our findings highlight the choice of discursive tactics that companies use to maintain control over strategic choices (Joutsenvirta, 2011; Joutsenvirta \& Vaara, 2015; Phillips et al., 2004). As obesity attracts much media attention, companies tend to respond by discursively negotiating the issue in the public debate (Calton \& Payne, 2003; Scherer \& Palazzo, 2007). With questioning, companies undermine the relevance of the social issue; with tying up, they weaken the strategic tension by bringing competing tensions around the issue to the fore; and with capturing, they portray themselves as taking part in the solution of the social issue. While the tactics that we found show great resemblance to Oliver's (1991) response 
strategies, our case concerned a widely salient issue, so acquiescence and defiance were not viable. Moreover, the companies were not consistent in their use of discursive tactics but blended them in seemingly contradictory ways. The tactics of questioning and tying up, which take a rather adversarial stance, seem at odds with capturing which is more accommodative. Nonetheless, we found many companies to be using all these tactics simultaneously which corroborates Joutsenvirta's (2011) findings that changes in societal norms and consumer behaviour can lead to 'rhetorical difficulties' for industries as it becomes almost impossible to consistently engage in one discourse.

The second underlying mechanism highlights that responses not only rely on the choice of discursive tactics but also how these tactics are employed for the de- and reconstruction of the strategic tension which echoes approaches in the literature that argue that tensions emanate from social constructions and interactions (Putnam et al., 2016). Through deconstruction, companies seek to neutralise the strategic tension between their core business and obesity. Through reconstruction, though, companies seek to alter the tension to weaken its effects on their business but not neutralise it altogether. While previous studies (Joutsenvirta, 2011; Joutsenvirta \& Vaara, 2015) have identified different discourses on social issues, such as the technocratic, societal, national-political and global-capitalist discourse, we uncover the process behind the discursive construction of tensions that allows companies to influence the public discourse.

Together, the two mechanisms explain the variety of accepting-defensive responses that we found in our data. Companies followed different response patterns to defend autonomy over their business, covering a range from more adversarial patterns, whereby companies seek to deactivate the strategic tension, to more accommodative ones, whereby companies appropriate the tension and engage in solving it. Yet, what all response patterns had in common was the underlying motive to either neutralise or weaken tensions with the aim to 
temporarily shield contested business practices and maintain autonomy over their strategy. Our findings thus link research on the discursive enactment of organisational responses to social issues (Phillips et al., 2004) to research on the underlying discursive processes of the social construction of tensions (Putnam et al., 2016). Accordingly, we argue that companies' responses to strategic tensions are inseparable from their discursive construction of tensions because our findings show that the purposeful de- and reconstruction of strategic tensions form an integral part of companies' responses to these tensions.

\section{Implications for the Literature on Organisational Tensions}

Our findings contribute to the literature on organisational tensions by going beyond the black-and-white picture of responses to strategic tensions as either rejecting-defensive or accepting-constructive (Lewis, 2000; Smith \& Lewis, 2011). The literature suggests that organisations reject strategic tensions to avoid inconsistencies and argues that rejection leads to vicious cycles and detrimental outcomes (Lewis, 2000; Sundaramurthy \& Lewis, 2003), because actors lean excessively to one pole of the tension. Alternatively, organisations accept tensions which encourages actors to embrace tensions (Smith \& Lewis, 2011) and implies that they develop constructive responses to engage with both poles of the tension, leading to virtuous cycles and desirable outcomes. In our analysis, only one response pattern (deactivating) rejects the tension between obesity and the core business of food and beverage companies, in which case companies failed to respond constructively to the tension. Given that obesity has turned into a widely salient social issue, we found that most companies in the food and drink industry tend to accept the tension and acknowledge that many of their products play a part in the obesity crisis.

In contrast to the predictions of the literature (Lewis, 2000; Smith \& Lewis, 2011), accepting the tension did not necessarily lead to constructive responses. Rather, we found a range of responses with only one response (appropriating) showing some evidence of more 
constructive responses where companies sought to contribute to tackle the obesity crisis. However, while companies responded in an active strategic manner, the response patterns we found were predominantly concerned with protecting companies' autonomy over the future direction of their core business. In a sense, this accepting-defensive approach is defensive but active and accepting at the same time and positioned in between the rejecting-defensive and accepting-constructive patterns that have been discussed in the literature on organisational tensions (Lewis, 2000; Smith \& Lewis, 2011). Hence, our findings suggest that there is more nuance in organisational responses to strategic tensions. From this perspective, managing tensions goes beyond 'capturing its enlightening potential' (Lewis, 2000: 763).

In the literature, the beneficial effects of accepting tensions have been attributed to the ability of organizations and leaders to integrate the contradictory poles of strategic tensions while acknowledging the relevance of both poles (Smith, Binns, \& Tushman, 2010). Smith, Besharov, Wessels, and Chertok (2012) distinguish three aspects of accepting-constructive responses to strategic social-business tensions: Acceptance, i.e., acknowledging competing demands, differentiation, i.e., recognizing the relevance of both poles of the strategic tension, and integration, i.e., addressing both poles of the tensions to seek synergies between them. Our findings confirm that "[a]ll three skills are necessary for managing the challenges posed by competing social and commercial demands" (Smith et al., 2012: 466). However, they also highlight that acquiring the ability to deploy an accepting-constructive approach to strategic tensions might require time, since not all three skills are present simultaneously. While most of the companies accepted the strategic tension around obesity and acknowledged both the need to fight obesity and their responsibility to contribute to this endeavour, they lacked the ability or willingness to develop synthetic responses to integrate the fight against obesity into their business models. Rather, most of them portrayed their core business and activities to 
address obesity as being separate with only few companies starting to engage in appropriating responses that involved more substantive changes to their offerings.

The accepting-defensive approach with its inherent imbalance, whereby most companies acknowledge the relevance to address obesity but still lean towards protecting their core business, seems to represent a transitory stage between rejecting-defensive and acceptingconstructive responses. As our findings indicate, in this transitory stage it remains open whether companies will fall back towards defensive approaches by overly emphasising their existing business model or if they will move towards more constructive responses by seeking ways to develop business models that integrate concerns about obesity. Our research thus contributes to a better understanding of the transition towards accepting-constructive responses and suggests that the acquisition of the necessary skills to deploy such responses requires time. Moreover, our findings suggest that such a transition may not only depend on enlightened leaders (Smith et al., 2012; Smith et al., 2010), but may also be driven by pressures from the organizational environment as illustrated by the public debate about widely salient social issues. Future research could address the factors that influence the development of the transitory accepting-defensive approach towards more constructive or more rejecting responses.

\section{Implications for the Literature on Corporate Social Responsibility}

By identifying the underlying mechanisms of corporate responses to strategic tensions around widely salient social issues (Bonardi \& Keim, 2005), we contribute to the CSR literature. We show that responses to widely salient social issues not only depend on the discursive tactics that companies employ but also on instrumentally de- and reconstructing the tensions around these social issues. Our findings suggest that the underlying reason for companies to discursively construct a social-business tension is its strategic nature (Putnam et al., 2016). Extant CSR literature has argued that social issues that become strategically 
important will motivate companies to follow a proactive approach to gain a competitive advantage (McWilliams \& Siegel, 2011; Porter \& Kramer, 2006). Our case of obesity shows instead that a social issue's strategic nature can also lead to a more defensive approach. While changes in consumer demand create opportunities to develop new markets for healthier alternatives, they pose a threat for the original product range that existing customers tend to prefer. The response patterns that we observed suggest that companies follow a defensive approach to protect core business practices because customers tend to adopt healthier options only progressively over time (Raghunathan et al., 2006).

Our findings closely correspond to and extend the deliberative approach to CSR (Scherer \& Palazzo, 2007). This approach argues that companies "do not simply follow powerful external expectations by complying with societal standards in legal and moral terms; they engage in discourses that aim at setting or redefining those standards and expectations in a changing, globalizing world and assume an enlarged political coresponsibility" (Scherer \& Palazzo, 2007: 1109). That is, companies take on an enlarged responsibility to solve social issues by engaging in the public debate (Scherer \& Palazzo, 2007). The widespread acceptance of obesity in our data as a public health issue that needs corporate involvement to solve corroborates deliberative CSR's relevance as a way to tackle grand challenges.

Nonetheless, our findings suggest that the process of companies assuming responsibility for solving social issues might be a double-edged sword. On the one hand, companies' involvement in the public debate on how social issues should be tackled can be a force for the good because it locks them into evolutionary pathways where they gradually transform their business practices and thus co-evolve with changing consumer preferences. As Scherer and Palazzo (2007: 1111) argued, “[a]lthough many firms enter these processes with a strategic attitude, they begin to acknowledge certain actors, stakes, and rules that they cannot reject at will subsequently". Indeed, the example of Robinsons shows that once healthier options have 
gained sufficient market share, it becomes much easier to scrap the original product range. On the other hand, once companies have become actively engaged in the public debate, they can also steer it in their own preferred direction, for example, by pushing for voluntary measures. Companies' half-hearted engagement in the Responsibility Deal illustrates this outcome.

\section{Implications for the Literature on Corporate Responses to Obesity and to SDGs}

With regard to the specific social issue of obesity, we offer a better understanding of the rather descriptive and dispersed findings from previous studies on corporate responses. The two underlying mechanisms we identified add more analytical structure to the analysis of companies' responses to the obesity crisis. We explicate that food companies' putting forward a lack of physical activity as the main cause of obesity (Karnani et al., 2014) represents a diluting response that relies on the mechanisms of reconstructing the strategic tensions and discursively questioning its relevance. Likewise, we show that the well-documented response of food and beverage companies of deactivating the strategic tension by referring to and funding counterfactual scientific evidence (Bes-Rastrollo, Schulze, Ruiz-Canela, \& MartinezGonzalez, 2013) relies on the mechanisms of deconstructing the strategic tension and discursively questioning its legitimacy and relevance.

Our findings also reveal that the manifold efforts of food and beverage companies to lobby against proposed interventions to address the obesity crisis, like product reformulation or food taxes, are using the mechanism of de- and reconstruction of the strategic tension around obesity. Food and drink companies' attempts to cast such interventions into a problematic light (Mialon et al., 2015; Nixon et al., 2015a) rely on the reconstruction of the strategic tension; they construct tensions between these interventions with other desirable competing outcomes such as job security or economic growth. Together with the discursive tactic of tying up in competing tensions, such a reconstruction effort results in destabilising responses that weaken the strategic tension around obesity. HFHS companies' attempts to 
shift the responsibility and tension around obesity onto consumers (Iivonen, 2018) rely on the mechanisms of deconstruction and tying up. Here, companies seek to neutralise the strategic tension by shifting; a third party — the consumer — is tied up in the strategic tension.

Furthermore, our findings show that food and drink companies' efforts to portray themselves as part of the solution to the obesity crisis (Nixon et al., 2015b) represent an appropriating response. This response relies on deconstruction and discursive capturing by leaving the impression of actively contributing to a solution and, hence, the elimination of the tension, even if the efforts to address obesity remain symbolic. Backgrounding represents a response using discursive capturing in combination with reconstruction. Companies seek to deemphasise the strategic tension around obesity by highlighting their contributions to solve tensions around other social issues, not necessarily related to food (Peloza et al., 2015; Richards et al., 2015). By purposefully putting solutions to tensions around alternative social issues to the fore, the tension around obesity is marginalised.

Our findings also offer insights into potential pathways for how businesses could play a more active role in achieving various SDGs. While strategic tensions around obesity reflect the "clash between the dominant business model [...] and a longer-term sustainability agenda" (Scheyvens, Banks, \& Hughes, 2016: 378), the range of accepting-defensive responses to obesity we found also provide starting points for more constructive contributions to SDGs. As discussed above, compared to more constructive responses to strategic tensions, accepting-defensive responses are characterised by a lack of integrative skills (Smith et al., 2012). Hence, they are situated between the ideal-typical "either/or" and "both/and" responses to tensions that are discussed in the literature and seem to represent transitory stages in between defensive and constructive responses. At the same time, our six response patterns differ in their degree of defensiveness. Except for the most defensive response (deactivating), companies accept the tension and — to a varying degree — acknowledge their role in 
addressing the obesity crisis.

These varying degrees of acceptance can be used as seeds for more constructive responses and the development of integrative skills. For instance, with all four responses of diluting, shifting, destabilising, and backgrounding, companies refer to the complexity of the obesity problem and highlight that it has many causes and layers, that it cannot be addressed by one actor alone, and that it is related to many other social issues. However, they tend to use this complexity in a defensive manner, i.e. as a justification for not adopting more constructive responses to obesity. Yet, acknowledging the inherent complexity of many SDGs represents an important condition for successfully implementing SDGs, as reflected by their conceptualization in terms of a water-energy-food nexus (Bieber et al., 2018). For companies relying on these responses, a next step towards more constructive approaches will be to embrace the complexity around SDGs. In this way, companies could engage with other actors in multi-stakeholder partnerships to develop common, collaborative solutions for SDGs (Bäckstrand, 2006) rather than shifting the responsibility upon other actors. By doing so, they will work through the complexity and interlinkages among the many causes and issues related to obesity and its connections to other SDGs, rather than using this complexity to dilute, destabilise, or background the relevance of obesity for their business.

When using the response pattern of appropriating, companies already accept that they need to be part of the solution to the obesity crisis. This response can serve as a starting point for a more integrative approach to the tensions between obesity and the business model of food and drink companies that goes beyond securing their strategic autonomy. Rather, accepting to play a role in the solution of SDGs may be a crucial step for developing appropriating responses towards more integrative approaches of business model innovations that accommodate both commercial objectives and addressing sustainability challenges (Evens et al., 2017; Richter, 2013) 
In sum, our findings on accepting-defensive responses offer insights into the responses to SDGs that firms adopt in the "transition era" towards truly sustainable business approaches (Shevchenko et al., 2016). At the same time, they provide starting points and trajectories for how accepting-defensive responses can be developed into more constructive ones.

\section{Limitations and Future Research}

Like most qualitative work, our study has certain limitations, for instance with regard to the generalisability of the findings. In the context of grand challenges related to the sustainable development goals (Eisenhardt, Graebner, \& Sonenshein, 2016; George et al., 2016; Howard-Grenville et al., 2017), more research is needed to address and better understand the uniqueness of these challenges and the implications they have for business. Future research could explore if companies use similar mechanisms based on the de- and reconstruction of tensions to protect their core business or use additional mechanisms to address other grand challenges. In our empirical analysis, we explored the responses and underlying mechanisms that company and industry representatives used in the public debate on obesity to protect the autonomy over the direction of their core business. However, we did not distinguish between companies regarding their individual exposure to obesity.

Stakeholder scrutiny and media attention with regard to social issues differ depending on companies' visibility, size, position in the market (B2B vs B2C), and brand name (Brammer \& Millington, 2006; Fombrun \& Shanley, 1990). Future studies could investigate whether some of the mechanisms we identified are more likely to be used by highly visible companies.

Our findings also reveal opportunities for research on corporate responses to strategic tensions, especially in the emerging field of tensions around social issues (Hahn et al., 2018; Hahn et al., 2015; Van der Byl \& Slawinski, 2015). As our analysis suggests, the acceptance and active management of tensions is not necessarily associated with constructive responses to social concerns but could well be used to avoid change and protect controversial business 
practices. Our findings show that companies deploy a range from more adversarial to more accommodative approaches, all with the aim to maintain autonomy over their core business, some of which include more substantive contributions to tackle social concerns.

Consequently, future research should address the individual, organisational, and field-level factors under which the acceptance of strategic tensions around widely salient social issues is likely to trigger opportunistic and symbolic responses or constructive and substantive responses instead.

Finally, we did not address the competitive dynamics among companies from the food and drink industry. Since obesity represents a collective crisis to the industry (Comyns \& Franklin-Johnson, 2018), future studies could look into the tactics and coordination mechanisms that companies use to protect their individual business model against the obesity crisis that affects them collectively taking into account the competitive dynamics among companies. Furthermore, our findings invite research that adopts a temporally dynamic perspective. The six-year period that we studied turned out to be too short to allow for theorising changes in the response patterns over time as they did not significantly change in these six years. Given the relatively long life cycle of widely salient social issues (Bonardi \& Keim, 2005; Mahon \& Waddock, 1992), longitudinal studies could analyse whether organisations use defensive responses to temporarily buffer vicious cycles and gain time with the aim to develop accepting-constructive responses, in due course. The accepting-defensive approach might well represent a transitory stage only and evolve into a stage where companies not only accept strategic tensions but also embrace and work through them (Lewis, 2000; Smith \& Lewis, 2011). From a glass-half-full perspective, the accepting-defensive approach could be an invaluable step in a slow process of industrial and behavioural change that will lock companies and their customers into a process where fighting obesity and achieving the SDGs become increasingly more central to their decision-making. 
TABLE 1

Number of coded newspaper articles

\begin{tabular}{cccccccc}
\hline & $\begin{array}{c}\text { Financial } \\
\text { Times }\end{array}$ & $\begin{array}{c}\text { The } \\
\text { Guardian }\end{array}$ & $\begin{array}{c}\text { The } \\
\text { Telegraph }\end{array}$ & $\begin{array}{c}\text { The } \\
\text { Grocer }\end{array}$ & $\begin{array}{c}\text { Just- } \\
\text { Food }\end{array}$ & $\begin{array}{c}\text { Food } \\
\text { Manufacture }\end{array}$ & Total \\
\hline $\mathbf{2 0 1 0}$ & 40 & 63 & 36 & 24 & 55 & 0 & $\mathbf{2 1 8}$ \\
\hline $\mathbf{2 0 1 1}$ & 23 & 25 & 39 & 25 & 23 & 0 & $\mathbf{1 3 5}$ \\
\hline $\mathbf{2 0 1 2}$ & 37 & 26 & 33 & 16 & 33 & 17 & $\mathbf{1 6 2}$ \\
\hline $\mathbf{2 0 1 3}$ & 36 & 48 & 63 & 42 & 28 & 21 & $\mathbf{2 3 8}$ \\
\hline $\mathbf{2 0 1 4}$ & 32 & 77 & 103 & 64 & 50 & 33 & $\mathbf{3 5 9}$ \\
\hline $\mathbf{2 0 1 5}$ & 35 & 144 & 101 & 83 & 40 & 22 & $\mathbf{4 2 5}$ \\
\hline Total & $\mathbf{2 0 3}$ & $\mathbf{3 8 3}$ & $\mathbf{3 7 5}$ & $\mathbf{2 5 4}$ & $\mathbf{2 2 9}$ & $\mathbf{9 3}$ & $\mathbf{1 5 3 7}$ \\
\hline
\end{tabular}


TABLE 2

Response patterns with exemplary quotes on company and industry level

\begin{tabular}{|c|c|c|c|}
\hline $\begin{array}{l}\text { Response } \\
\text { pattern }\end{array}$ & Content of response & $\begin{array}{l}\text { Level of } \\
\text { response }\end{array}$ & Exemplary quotes \\
\hline \multirow{2}{*}{ Deactivating } & \multirow{2}{*}{$\begin{array}{l}\text { Challenge the underlying scientific } \\
\text { evidence on the link between HFHS foods } \\
\text { and obesity by highlighting or supporting } \\
\text { studies that provide counterfactual evidence }\end{array}$} & Company & $\begin{array}{l}\text { "Sugar \& health, Sugar gets a lot of bad press, and we are frequently being told to 'watch } \\
\text { out for sugar'. But why is this? Is it detrimental to health? Let's see what the experts say." } \\
\text { Kellogg said an independent dietician had gathered medical evidence from a World Health } \\
\text { Organisation committee, that concluded "a high sugar intake is not related to obesity, or the } \\
\text { development of diseases such as heart disease, diabetes, high blood pressure or cancer". } \\
\text { (Just-Food, Watchdog rules Kellogg sugar claim "misleading", 9 March 2012) }\end{array}$ \\
\hline & & Industry & $\begin{array}{l}\text { However, a spokesman from Sugar Nutrition, which promotes sugar's benefits said its } \\
\text { connection with obesity was not supported by the consensus of scientific evidence. "The } \\
\text { international authority, the World Health Organisation (WHO), funded a review on sugar } \\
\text { and obesity published last year which concluded that any link to body weight was due to } \\
\text { overconsumption of calories and was not specific to sugars," said the spokesman. (Food } \\
\text { Manufacture, Cutting sugar from recipes 'just isn't that simple', 1 February 2014) }\end{array}$ \\
\hline \multirow{2}{*}{ Diluting } & \multirow{2}{*}{$\begin{array}{l}\text { Highlight alternative or additional factors } \\
\text { that contribute to obesity to discursively } \\
\text { question whether business activities } \\
\text { represent the main cause for obesity }\end{array}$} & Company & $\begin{array}{l}\text { However, Bulcke [CEO of Nestlé] argued, assigning blame and placing responsibility } \\
\text { squarely at the door of the industry fails to recognise the complex nature of the obesity } \\
\text { crisis, which encompasses myriad issues from poverty to our now prevalent sedentary } \\
\text { lifestyles. "It doesn't help to blame only one part [of the chain]... There is not one solution, } \\
\text { there are many solutions that have to converge," he insisted. (Just-Food, Threat of } \\
\text { legislation on obesity looms large, } 18 \text { January 2013) }\end{array}$ \\
\hline & & Industry & $\begin{array}{l}\text { The British Soft Drinks Association says that consumption of soft drinks containing added } \\
\text { sugar has fallen by } 9 \% \text { over the last } 10 \text { years, while the incidence of obesity has risen by } \\
15 \% \text {. "Obesity is a serious and complex problem requiring concerted action by a wide } \\
\text { range of organisations as well as by people themselves. Soft drinks companies recognise } \\
\text { the role they have to play," it said. (The Guardian, Don't assume smoothies are good for } \\
\text { you, scientists say, } 7 \text { September 2013) }\end{array}$ \\
\hline Shifting & $\begin{array}{l}\text { Shift the responsibility for obesity away } \\
\text { from business onto consumers by pointing } \\
\text { at the importance of a healthy lifestyle, } \\
\text { physical exercise and the 'energy balance' }\end{array}$ & Company & $\begin{array}{l}\text { An Aldi spokesperson also stressed that the retailer offers consumers a choice and the } \\
\text { option to buy healthier products. "We continue to offer our customers healthier options } \\
\text { through a number of initiatives such as our Super } 6 \text { fruit and veg promotion, which offers } \\
\text { customers access to quality produce at affordable prices. We also recently launched our Be } \\
\text { Light ready meals range, which is the only fully green rated ready meal available on the } \\
\text { market." (Just-Food, News Cereal faces fresh criticism over sugar content, } 30 \text { January } \\
\text { 2015) }\end{array}$ \\
\hline
\end{tabular}




\begin{tabular}{|c|c|c|c|}
\hline & & Industry & $\begin{array}{l}\text { But the food and drink industry insists that obesity is a lifestyle problem based on eating } \\
\text { too much and exercising too little. Barbara Gallani, a director at the UK's Food and Drink } \\
\text { Federation, a lobby group, criticised "hysterical food and nutrition messages we are } \\
\text { increasingly seeing peddled by a range of stakeholders often focus on individual nutrients } \\
\text { and [are] rarely backed by robust or up-to-date science". (Financial Times, US sugar } \\
\text { industry attacks 'misleading' WHO guidelines, } 4 \text { March } 2015 \text {. }\end{array}$ \\
\hline \multirow{2}{*}{ Destabilising } & \multirow{2}{*}{$\begin{array}{l}\text { Introduce a competing tension to destabilise } \\
\text { interventions or proposed measures to } \\
\text { tackle obesity by highlighting the } \\
\text { unintended consequences or ineffectiveness } \\
\text { of such measures }\end{array}$} & Company & $\begin{array}{l}\text { "Getting people to accept stevia as an alternative to sugar is a challenge as it has an after- } \\
\text { taste some people simply don't like," says Logan at Refresco Gerber, which is blending } \\
\text { juices with aloe vera to cut sugar. But sugar will always play a part. "If we're going to crack } \\
\text { the mass market we need to look at blends that include some sugar for mouthfeel and } \\
\text { flavour, not remove it altogether. This is how you begin weaning people off higher-sugar } \\
\text { juices and juice drinks." (The Grocer, Juices \& Smoothies Category Report 2015, } 28 \\
\text { February 2015) }\end{array}$ \\
\hline & & Industry & $\begin{array}{l}\text { The Food and Drink Federation said it shared the BMA's concerns about the health of } \\
\text { young people, who needed "better, more balanced diets and lifestyles". But its director } \\
\text { general, Ian Wright added: "Many foods and drinks are already taxed at } 20 \% \text {. Where } \\
\text { additional taxes have been introduced they've not proven effective at driving long-term, } \\
\text { lasting change to diets. (The Guardian, Doctors demand a } 20 \% \text { tax on sugary drinks to fight } \\
\text { UK obesity epidemic, } 14 \text { July 2015) }\end{array}$ \\
\hline \multirow{2}{*}{ Appropriating } & \multirow{2}{*}{$\begin{array}{l}\text { Create a public perception of actively taking } \\
\text { part in the fight against obesity by claiming } \\
\text { that measures such as product reformulation } \\
\text { and 'delivery of choice' solve the problem }\end{array}$} & Company & $\begin{array}{l}\text { Nestlé and other big firms have pledged to rebuild public trust by clearly labelling the } \\
\text { nutritional content on all products and agreeing not to advertise junk food to children. } \\
\text { They announced several measures to try to improve the industry's image, including not } \\
\text { targeting children under the age of } 12 \text { with products which do not meet certain nutrition } \\
\text { criteria and to introduce industry-wide labelling by } 2018 \text { to help consumers choose healthy } \\
\text { options. (The Telegraph, World food giants promise a more ethical approach, 19 June } \\
\text { 2014) }\end{array}$ \\
\hline & & Industry & $\begin{array}{l}\text { That's one reason why } 60 \% \text { of soft drink sales in the UK are of low or no-calorie products, } \\
\text { according to the British Soft Drinks Association's analysis of the category. It's a trend that } \\
\text { has been accelerating in recent years, as leading companies such as ours have committed to } \\
\text { reduce the calories per litre across our portfolio. In our case, we made a pledge as part of } \\
\text { the Department of Health's Responsibility Deal to reduce the average calories per litre of } \\
\text { our range of sparkling drinks by } 5 \% \text { per litre over a three-year period. (The Grocer, Why } \\
\text { Coke is launching Coca-Cola Life, } 14 \text { June 2014) }\end{array}$ \\
\hline Backgrounding & $\begin{array}{l}\text { Put positive contributions to the fore that } \\
\text { address and solve tensions around other } \\
\text { social issues, unrelated to obesity }\end{array}$ & Company & $\begin{array}{l}\text { A McDonald's spokeswoman said the } \$ 5 \text { Feed was introduced on January } 31 \text { and would run } \\
\text { until March } 1 \text {. "We aim to provide choice to all our customers, and for those looking for a } \\
\text { healthier option there is also a Heart Tick Approved } \$ 5 \text { Feed available," she said. } \\
\text { Hungry Jack's said in a statement: "We are proud to offer our customers great tasting } \\
\text { meals at an affordable price, which is especially relevant during these challenging } \\
\text { economic times." (Sunday Telegraph, Fat deals conning our kids, } 13 \text { February 2011) }\end{array}$ \\
\hline
\end{tabular}




\begin{tabular}{|l|l|l|}
\hline & & $\begin{array}{l}\text { When I took over the reins at the FDF earlier this year, I assumed I would spend my time } \\
\text { talking about skills, productivity and sustainability. British food and drink producers' hard- } \\
\text { earned reputation for quality is driving export sales of close to £13bn. We employ around } \\
400,000 \text { people in the UK, and many more across the supply chain. We are on track to meet } \\
\text { our 0\% waste to landfill target by the end of the year and this year met a stretching carbon } \\
\text { reduction target six years early. But instead of being fully able to extol the contribution of } \\
\text { UK food \& drink, since the summer I have had to defend the sector from unjust and } \\
\text { unrelenting attack by the health lobby. (The Grocer, Time to stop the blame game on } \\
\text { obesity, 5 December 2015) }\end{array}$ \\
\hline
\end{tabular}


FIGURE 1

Underlying mechanisms of accepting-defensive responses

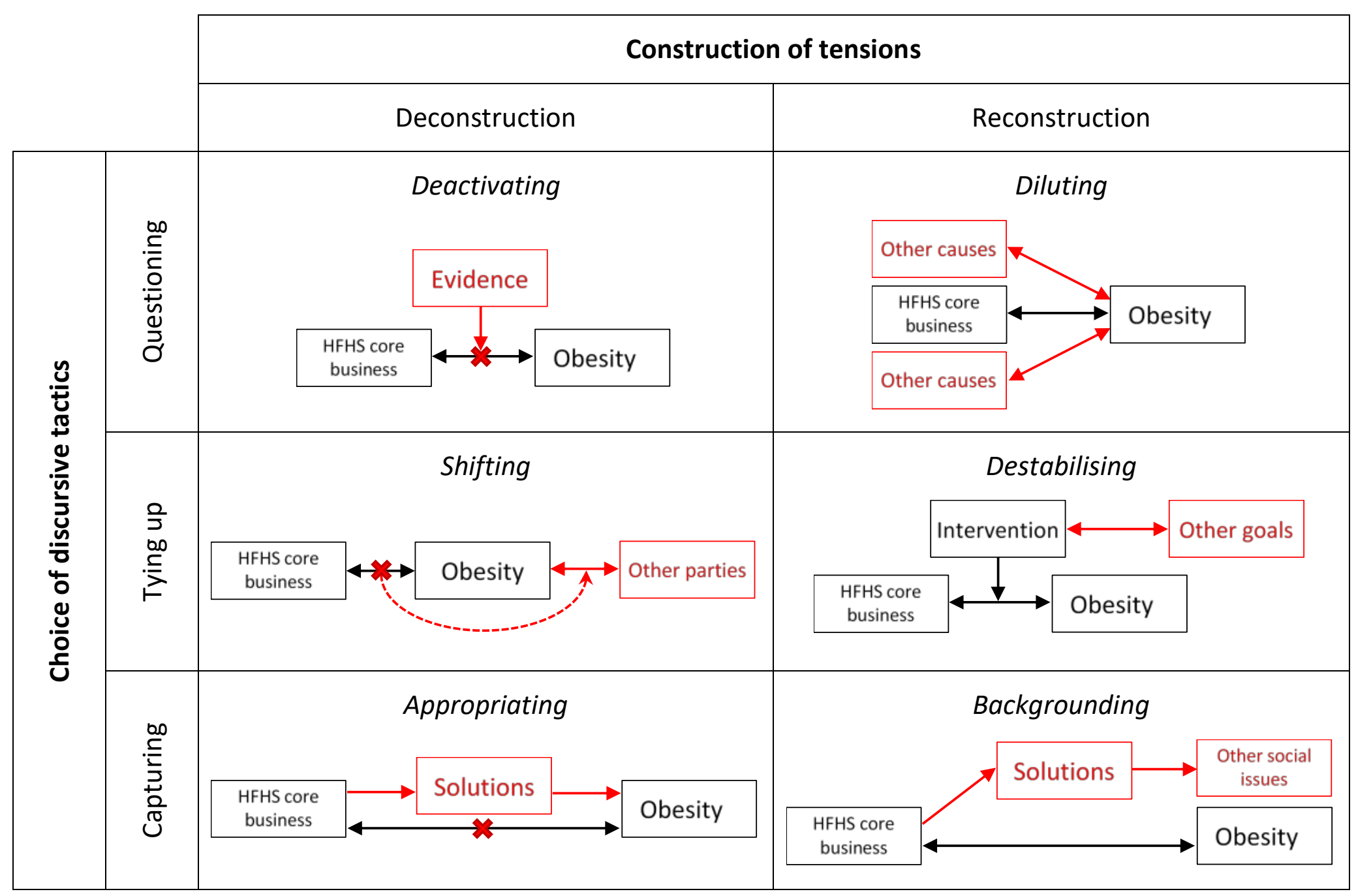




\section{REFERENCES}

Andreyeva, T., Kelly, I. R., \& Harris, J. L. 2011. Exposure to food advertising on television: Associations with children's fast food and soft drink consumption and obesity. Economics \& Human Biology, 9(3): 221-233; doi: 10.1016/j.ehb.2011.02.004.

Ariño, A., LeBaron, C., \& Milliken, F. J. 2016. Publishing Qualitative Research in Academy of Management Discoveries. Academy of Management Discoveries, 2(2): 109-113; doi: 10.5465/amd.2016.0034.

Bäckstrand, K. 2006. Multi-stakeholder partnerships for sustainable development: rethinking legitimacy, accountability and effectiveness. European Environment, 16(5): 290-306; doi: 10.1002/eet.425.

Battilana, J., Sengul, M., Pache, A.-C., \& Model, J. 2015. Harnessing Productive Tensions in Hybrid Organizations: The Case of Work Integration Social Enterprises. Academy of Management Journal, 58(6): 1658-1685; doi: 10.5465/amj.2013.0903.

Beech, N., Burns, H., de Caestecker, L., MacIntosh, R., \& MacLean, D. 2004. Paradox as invitation to act in problematic change situations. Human Relations, 57(10): 1313-1332; doi: $10.1177 / 0018726704048357$.

Berger, I. E., Cunningham, P. H., \& Drumwright, M. E. 2007. Mainstreaming Corporate Social Responsibility: Developing Markets for Virtue. California Management Review, 49(4): 132-157; doi: 10.2307/41166409.

Bes-Rastrollo, M., Schulze, M. B., Ruiz-Canela, M., \& Martinez-Gonzalez, M. A. 2013. Financial conflicts of interest and reporting bias regarding the association between sugarsweetened beverages and weight gain: a systematic review of systematic reviews. PLoS Medicine, 10(12): e1001578; doi: 10.1371/journal.pmed.1001578.

Bieber, N., Ker, J. H., Wang, X., Triantafyllidis, C., van Dam, K. H., Koppelaar, R. H. E. M., $\&$ Shah, N. 2018. Sustainable planning of the energy-water-food nexus using decision making tools. Energy Policy, 113: 584-607; doi: 10.1016/j.enpol.2017.11.037.

Bonardi, J.-P., \& Keim, G. D. 2005. Corporate Political Strategies for Widely Salient Issues. Academy of Management Review, 30(3): 555-576; doi: 10.5465/amr.2005.17293705.

Brammer, S., \& Millington, A. 2006. Firm size, organizational visibility and corporate philanthropy: An empirical analysis. Business Ethics: A European Review, 15(1): 6-18; doi: 10.1111/j.1467-8608.2006.00424.x.

Brownell, K. D., Farley, T., Willett, W. C., Popkin, B. M., Chaloupka, F. J., Thompson, J. W., \& Ludwig, D. S. 2009. The Public Health and Economic Benefits of Taxing SugarSweetened Beverages. New England Journal of Medicine, 361(16): 1599-1605; doi: doi:10.1056/NEJMhpr0905723.

Brownell, K. D., \& Warner, K. E. 2009. The Perils of Ignoring History: Big Tobacco Played Dirty and Millions Died. How Similar Is Big Food? Milbank Quarterly, 87(1): 259-294; doi: 10.1111/j.1468-0009.2009.00555.x.

Calton, J. M., \& Payne, S. L. 2003. Coping with paradox: Multistakeholder learning dialogue as a pluralist sensemaking process for addressing messy problems. Business \& Society, 42(1): 7-42; doi: 10.1177/0007650302250505.

Comyns, B., \& Franklin-Johnson, E. 2018. Corporate Reputation and Collective Crises: A Theoretical Development Using the Case of Rana Plaza. Journal of Business Ethics, 150(1): 159-183; doi: 10.1007/s10551-016-3160-4.

Darmon, K., Fitzpatrick, K., \& Bronstein, C. 2008. Krafting the obesity message: A case study in framing and issues management. Public Relations Review, 34(4): 373-379; doi:

10.1016/j.pubrev.2008.07.002. 
Du, S., \& Vieira, E. T. 2012. Striving for Legitimacy Through Corporate Social Responsibility: Insights from Oil Companies. Journal of Business Ethics, 110(4): 413-427; doi: 10.1007/s10551-012-1490-4.

Ebbeling, C. B., Pawlak, D. B., \& Ludwig, D. S. 2002. Childhood obesity: public-health crisis, common sense cure. The Lancet, 360(9331): 473-482; doi: 10.1016/S0140-6736(02)096782.

Eisenhardt, K. M., Graebner, M. E., \& Sonenshein, S. 2016. Grand Challenges and Inductive Methods: Rigor without Rigor Mortis. Academy of Management Journal, 59(4): 11131123; doi: 10.5465/amj.2016.4004.

Estrel, M., \& Bauerlein, V. 2011. PepsiCo Wakes Up and Smells the Cola, The Wall Street Journal, 28 June 2011.

Evans, S., Vladimirova, D., Holgado, M., Van Fossen, K., Yang, M., Silva, E. A., \& Barlow, C. Y. 2017. Business Model Innovation for Sustainability: Towards a Unified Perspective for Creation of Sustainable Business Models. Business Strategy and the Environment, 26(5): 597-608; doi: 10.1002/bse.1939.

Fombrun, C., \& Shanley, M. 1990. What's in a Name? Reputation Building and Corporate Strategy. Academy of Management Journal, 33(2): 233-258; doi: 10.5465/256324.

Fulponi, L. 2006. Private voluntary standards in the food system: The perspective of major food retailers in OECD countries. Food Policy, 31(1): 1-13; doi: 10.1016/j.foodpol.2005.06.006.

Gebert, D., Boerner, S., \& Kearney, E. 2010. Fostering Team Innovation: Why Is It Important to Combine Opposing Action Strategies? Organization Science, 21(3): 593-608; doi: 10.1287/orsc.1090.0485.

George, G., Howard-Grenville, J., Joshi, A., \& Tihanyi, L. 2016. Understanding and Tackling Societal Grand Challenges through Management Research. Academy of Management Journal, 59(6): 1880-1895; doi: 10.5465/amj.2016.4007.

Hahn, T., Figge, F., Pinkse, J., \& Preuss, L. 2018. A Paradox Perspective on Corporate Sustainability: Descriptive, Instrumental, and Normative Aspects. Journal of Business Ethics, 148(2): 235-248; doi: 10.1007/s10551-017-3587-2.

Hahn, T., Pinkse, J., Preuss, L., \& Figge, F. 2015. Tensions in Corporate Sustainability: Towards an Integrative Framework. Journal of Business Ethics, 127(2): 297-316; doi: 10.1007/s10551-014-2047-5.

Hahn, T., Pinkse, J., Preuss, L., \& Figge, F. 2016. Ambidexterity for Corporate Social Performance. Organization Studies, 37(2): 213-235; doi: 10.1177/0170840615604506.

Hahn, T., Preuss, L., Pinkse, J., \& Figge, F. 2014. Cognitive Frames in Corporate Sustainability: Managerial Sensemaking with Paradoxical and Business Case Frames. Academy of Management Review, 39(4): 463-487; doi: 10.5465/amr.2012.0341.

Harris, J. L., LoDolce, M. E., \& Schwartz, M. B. 2015. Encouraging big food to do the right thing for children's health: A case study on using research to improve marketing of sugary cereals. Critical Public Health, 25(3): 320-332; doi: 10.1080/09581596.2014.957655.

Hedström, P., \& Swedberg, R. 1998. Social mechanisms: An introductory essay. In P. Hedström, \& R. Swedberg (Eds.), Social Mechanisms: An Analytical Approach to Social Theory: 1-31. Cambridge, U.K.: Cambridge University Press.

Hieke, S., \& Taylor, C. R. 2012. A Critical Review of the Literature on Nutritional Labeling. Journal of Consumer Affairs, 46(1): 120-156; doi: 10.1111/j.1745-6606.2011.01219.x.

Howard-Grenville, J., Davis, J., Dyllick, T., Joshi, A., Miller, C., Thau, S., \& Tsui, A. S. 2017. Sustainable Development for a Better World: Contributions of Leadership, Management and Organizations. Academy of Management Discoveries, 3(1): 107-110; doi: 10.5465/amd.2017.0023. 
Hruby, A., \& Hu, F. 2015. The Epidemiology of Obesity: A Big Picture. PharmacoEconomics, 33(7): 673-689; doi: 10.1007/s40273-014-0243-x.

Iivonen, K. 2018. Defensive Responses to Strategic Sustainability Paradoxes - Have Your Coke and Drink It Too! Journal of Business Ethics, 148(2): 309-327; doi: 10.1007/s 10551-0173580-9.

James, P. T., Leach, R., Kalamara, E., \& Shayeghi, M. 2001. The Worldwide Obesity Epidemic. Obesity Research, 9(S11): 228S-233S; doi: 10.1038/oby.2001.123.

Jarzabkowski, P., Lê, J. K., \& Van de Ven, A. H. 2013. Responding to competing strategic demands: How organizing, belonging, and performing paradoxes coevolve. Strategic Organization, 11(3): 245-280; doi: 10.1177/1476127013481016.

Jarzabkowski, P. A., \& Lê, J. K. 2017. We have to do this and that? You must be joking: Constructing and responding to paradox through humor. Organization Studies, 38(3-4): 433-462; doi: 10.1177/0170840616640846.

Jebb, S. A., Aveyard, P. N., \& Hawkes, C. 2013. The evolution of policy and actions to tackle obesity in England. Obesity Reviews, 14(Suppl. 2): 42-59; doi: 10.1111/obr.12093.

Joutsenvirta, M. 2011. Setting Boundaries for Corporate Social Responsibility: Firm-NGO Relationship as Discursive Legitimation Struggle. Journal of Business Ethics, 102(1): 57 75.

Joutsenvirta, M., \& Vaara, E. 2015. Legitimacy struggles and political corporate social responsibility in international settings: A comparative discursive analysis of a contested investment in Latin America. Organization Studies, 36(6): 741-777; doi: $0.1177 / 0170840615571958$.

Karnani, A., McFerran, B., \& Mukhopadhyay, A. 2014. Leanwashing: A Hidden Factor in the Obesity Crisis. California Management Review, 56(4): 5-30: doi: 10.1525/cmr.2014.56.4.5.

Kleiman, S., Ng, S. W., \& Popkin, B. 2012. Drinking to our health: Can beverage companies cut calories while maintaining profits? Obesity Reviews, 13(3): 258-274; doi: 10.1111/j.1467-789X.2011.00949.x.

Kolk, A., Hsin-Hsuan Meg, L., \& Van Dolen, W. 2012. A Fat Debate on Big Food? Unraveling Blogosphere Reactions. California Management Review, 55(1): 47-73; doi: 10.1525/cmr.2012.55.1.47.

Lewis, M. W. 2000. Exploring Paradox: Toward a More Comprehensive Guide. Academy of Management Review, 25(4): 760-776; doi: 10.2307/259204.

Lüscher, L. S., \& Lewis, M. W. 2008. Organizational Change and Managerial Sensemaking: Working Through Paradox. Academy of Management Journal, 51(2): 221-240; doi: 10.5465/AMJ.2008.31767217.

Maguire, S., \& Hardy, C. 2009. Discourse and deinstitutionalization: The decline of DDT. Academy of Management Journal, 52(1): 148-178; doi: 10.5465/amj.2009.36461993.

Mahon, J. F., \& Waddock, S. A. 1992. Strategic issues management: An integration of issue life cycle perspectives. Business \& Society, 31(1): 19-32; doi: 10.1177/000765039203100103.

McWilliams, A., \& Siegel, D. S. 2011. Creating and Capturing Value: Strategic Corporate Social Responsibility, Resource-Based Theory, and Sustainable Competitive Advantage. Journal of Management, 37(5): 1480-1495; doi: 10.1177/0149206310385696.

Mialon, M., Swinburn, B., \& Sacks, G. 2015. A proposed approach to systematically identify and monitor the corporate political activity of the food industry with respect to public health using publicly available information. Obesity Reviews, 16(7): 519-530; doi:

10.1111/obr.12289. 
Miron-Spektor, E., Gino, F., \& Argote, L. 2011. Paradoxical frames and creative sparks: Enhancing individual creativity through conflict and integration. Organizational Behavior and Human Decision Processes, 116(2): 229-240; doi: 10.1016/j.obhdp.2011.03.006.

Moodie, R., Stuckler, D., Monteiro, C., Sheron, N., Neal, B., Thamarangsi, T., Lincoln, P., \& Casswell, S. 2013. Profits and pandemics: Prevention of harmful effects of tobacco, alcohol, and ultra-processed food and drink industries. The Lancet, 381(9867): 670-679; doi: 10.1016/S0140-6736(12)62089-3.

Mudd, M. 2013. How to Force Ethics on the Food Industry, The New York Times, 16 March 2013.

Nixon, L., Mejia, P., Cheyne, A., \& Dorfman, L. 2015a. Big Soda's long shadow: news coverage of local proposals to tax sugar-sweetened beverages in Richmond, El Monte and Telluride. Critical Public Health, 25(3): 333-347; doi: 10.1080/09581596.2014.987729.

Nixon, L., Mejia, P., Cheyne, A., Wilking, C., Dorfman, L., \& Daynard, R. 2015b. "We're Part of the Solution": Evolution of the Food and Beverage Industry's Framing of Obesity Concerns Between 2000 and 2012. American Journal of Public Health, 105(11): 22282236; doi: 10.2105/AJPH.2015.302819.

Oliver, C. 1991. Strategic Responses to Institutional Processes. Academy of Management Review, 16(1): 145-179; doi: 10.5465/amr.1991.4279002.

Papoutsi, G. S., Drichoutis, A. C., \& Nayga, R. M. 2013. The Causes of Childhood Obesity: A Survey. Journal of Economic Surveys, 27(4): 743-767; doi: 10.1111/j.14676419.2011.00717.x.

Peloza, J., Ye, C., \& Montford, W. J. 2015. When Companies Do Good, Are Their Products Good for You? How Corporate Social Responsibility Creates a Health Halo. Journal of Public Policy \& Marketing, 34(1): 19-31; doi: 10.1509/jppm.13.037.

Phillips, N., Lawrence, T. B., \& Hardy, C. 2004. Discourse and Institutions. Academy of Management Review, 29(4): 635-652; doi: 10.5465/amr.2004.14497617.

Porter, M. E., \& Kramer, M. R. 2006. Strategy and Society: The Link Between Competitive Advantage and Corporate Social Responsibility. Harvard Business Review, 84(12): 78-92.

Putnam, L. L., Fairhurst, G. T., \& Banghart, S. 2016. Contradictions, Dialectics, and Paradoxes in Organizations: A Constitutive Approach. Academy of Management Annals, 10(1): 65 171; doi: 10.1080/19416520.2016.1162421.

Raghunathan, R., Naylor, R. W., \& Hoyer, W. D. 2006. The Unhealthy = Tasty Intuition and Its Effects on Taste Inferences, Enjoyment, and Choice of Food Products. Journal of Marketing, 70(4): 170-184; doi: 10.1509/jmkg.70.4.170.

Richards, Z., Thomas, S. L., Randle, M., \& Pettigrew, S. 2015. Corporate Social Responsibility programs of Big Food in Australia: A content analysis of industry documents. Australian and New Zealand Journal of Public Health, 39(6): 550-556; doi: 10.1111/17536405.12429.

Richter, M. 2013. Business model innovation for sustainable energy: German utilities and renewable energy. Energy Policy, 62: 1226-1237; doi: 10.1016/j.enpol.2013.05.038.

Sacks, G., Mialon, M., Vandevijvere, S., Trevena, H., Snowdon, W., Crino, M., \& Swinburn, B. 2015. Comparison of food industry policies and commitments on marketing to children and product (re)formulation in Australia, New Zealand and Fiji. Critical Public Health, 25(3): 299-319; doi: 10.1080/09581596.2014.946888.

Schad, J., Lewis, M. W., Raisch, S., \& Smith, W. K. 2016. Paradox Research in Management Science: Looking Back to Move Forward. Academy of Management Annals, 10(1): 5-64; doi: 10.1080/19416520.2016.1162422.

Scherer, A. G., \& Palazzo, G. 2007. Toward a political conception of corporate responsibility: Business and society seen from a Habermasian perspective. Academy of Management Review, 32(4): 1096-1120; doi: 10.5465/amr.2007.26585837. 
Scherer, A. G., \& Palazzo, G. 2011. The New Political Role of Business in a Globalized World: A Review of a New Perspective on CSR and its Implications for the Firm, Governance, and Democracy. Journal of Management Studies, 48(4): 899-931; doi: 10.1111/j.14676486.2010.00950.x.

Schrempf, J. 2014. A Social Connection Approach to Corporate Responsibility: The Case of the Fast-Food Industry and Obesity. Business \& Society, 53(2): 300-332; doi: $10.1177 / 0007650312449577$.

Scheyvens, R., Banks, G., \& Hughes, E. 2016. The Private Sector and the SDGs: The Need to Move Beyond 'Business as Usual'. Sustainable Development, 24(6): 371-382; doi: $10.1002 / \mathrm{sd} .1623$.

Sharma, G., \& Good, D. 2013. The Work of Middle Managers: Sensemaking and Sensegiving for Creating Positive Social Change. The Journal of Applied Behavioral Science, 49(1): 95-122; doi: 10.1177/0021886312471375.

Shevchenko, A., Lévesque, M., \& Pagell, M. 2016. Why Firms Delay Reaching True Sustainability. Journal of Management Studies, 53(5): 911-935; doi: 10.1111/joms.12199.

Simon, M. 2012a. A leopard like PepsiCo cannot change its spots, The Guardian, 21 March 2012.

Simon, M. 2012b. PepsiCo and Public Health: Is the Nation's Largest Food Company a Model of Corporate Responsibility or Master of Public Relations? Cuny Law Review, 15(9): 9-26.

Sisnowski, J., Handsley, E., \& Street, J. M. 2015. Regulatory approaches to obesity prevention: A systematic overview of current laws addressing diet-related risk factors in the European Union and the United States. Health Policy, 119(6): 720-731; doi: 10.1016/j.healthpol.2015.04.013.

Smith, K. B., \& Smith, M. S. 2016. Obesity Statistics. Primary Care: Clinics in Office Practice, 43(1): 121-135; doi: 10.1016/j.pop.2015.10.001.

Smith, K. K., \& Berg, D. N. 1987. Paradoxes of group life: Understanding conflict, paralysis, and movement in group dynamics. San Francisco: Jossey-Bass.

Smith, W. K. 2014. Dynamic Decision Making: A Model of Senior Leaders Managing Strategic Paradoxes. Academy of Management Journal, 57(6): 1592-1623; doi: 10.5465/amj.2011.0932.

Smith, W. K., Besharov, M. L., Wessels, A. K., \& Chertok, M. 2012. A paradoxical leadership model for social entrepreneurs: Challenges, leadership skills, and pedagogical tools for managing social and commercial demands. Academy of Management Learning \& Education, 11(3): 463-478; doi: 10.5465/amle.2011.0021.

Smith, W. K., Binns, A., \& Tushman, M. L. 2010. Complex business models: Managing strategic paradoxes simultaneously. Long Range Planning, 43(2-3): 448-461; doi: 10.1016/j.lrp.2009.12.003.

Smith, W. K., Gonin, M., \& Besharov, M. L. 2013. Managing Social-Business Tensions: A Review and Research Agenda for Social Enterprise. Business Ethics Quarterly, 23(3): 407442; doi: 10.5840/beq201323327.

Smith, W. K., \& Lewis, M. W. 2011. Toward a theory of paradox: A dynamic equilibrium model of organizing. Academy of Management Review, 36(2): 381-403; doi: 10.5465/amr.2011.59330958.

Stuckler, D., McKee, M., Ebrahim, S., \& Basu, S. 2012. Manufacturing Epidemics: The Role of Global Producers in Increased Consumption of Unhealthy Commodities Including Processed Foods, Alcohol, and Tobacco. PLoS Medicine, 9(6): e1001235; doi: 10.1371/journal.pmed.1001235.

Stuckler, D., \& Nestle, M. 2012. Big Food, Food Systems, and Global Health. PLoS Medicine, 9(6): e1001242; doi: 10.1371/journal.pmed.1001242. 
Sundaramurthy, C., \& Lewis, M. 2003. Control and Collaboration: Paradoxes of Governance. Academy of Management Review, 28(3): 397-415; doi: 10.5465/amr.2003.10196737.

Swinburn, B., Kraak, V., Rutter, H., Vandevijvere, S., Lobstein, T., Sacks, G., Gomes, F., Marsh, T., \& Magnusson, R. 2015. Strengthening of accountability systems to create healthy food environments and reduce global obesity. The Lancet, 385(9986): 2534-2545; doi: 10.1016/S0140-6736(14)61747-5.

Swinburn, B. A., Sacks, G., Hall, K. D., McPherson, K., Finegood, D. T., Moodie, M. L., \& Gortmaker, S. L. 2011. The global obesity pandemic: shaped by global drivers and local environments. The Lancet, 378(9793): 804-814; doi: 10.1016/S0140-6736(11)60813-1.

The PLoS Medicine Editors. 2012. The Food Industry Is Ripe for Scrutiny. PLoS Medicine, 9(6): e1001246; doi: 10.1371/journal.pmed.1001246.

Vallgårda, S. 2015a. English obesity policies: To govern and not to govern. Health Policy, 119(6): 743-748; doi: 10.1016/j.healthpol.2015.02.015.

Vallgårda, S. 2015b. Governing obesity policies from England, France, Germany and Scotland. Social Science \& Medicine, 147: 317-323; doi: 10.1016/j.socscimed.2015.11.006.

Van der Byl, C. A., \& Slawinski, N. 2015. Embracing Tensions in Corporate Sustainability: A Review of Research From Win-Wins and Trade-Offs to Paradoxes and Beyond. Organization \& Environment, 28(1): 54-79; doi: 10.1177/1086026615575047.

Wansink, B., \& Huckabee, M. 2005. De-Marketing Obesity. California Management Review, 47(4): 6-18; doi: 10.2307/41166314. 
Jonatan Pinkse (jonatan.pinkse@manchester.ac.uk) is a full professor at Alliance Manchester Business School, University of Manchester, UK and executive director of the Manchester Institute of Innovation Research. He received his doctorate from the University of Amsterdam. His research interests include paradoxes and tensions in business sustainability, corporate responses to climate change, and business model innovation in energy and mobility.

Tobias Hahn (tobias.hahn@esade.edu) is a full professor at ESADE Business School, Ramon Llull University in Barcelona, Spain and honorary professor at the University of Sydney Business School, Australia. He received his doctorate from the University of Lüneburg. His research interests include paradoxes and tensions in business sustainability, sustainable business strategies, and the assessment of corporate sustainability performance.

Frank Figge (figge@sustainablevalue.com) is senior professor at KEDGE Business School in Marseille, France and visiting professor at Macquarie Business School in Sydney, Australia. He received his doctorate from the University of Basle, Switzerland. His research interests include tensions in corporate sustainability, sustainable business strategies, evolution and sustainability, and circular economy. 